Bilingualism: Language and Cognition

http://journals.cambridge.org/BIL

Additional services for Bilingualism: Language and Cognition:

Email alerts: $\underline{\text { Click here }}$

Subscriptions: $\underline{\text { Click here }}$

Commercial reprints: Click here

Terms of use : Click here

\title{
The acquisition of possessive HAVE-clauses by Turkish and Moroccan learners of Dutch
}

Ineke van de Craats, Roeland van Hout and Norbert Corver

Bilingualism: Language and Cognition / Volume 5 / Issue 02 / August 2002, pp 147 - 174

DOI: 10.1017/S136672890200024X, Published online: 06 August 2002

Link to this article: http://journals.cambridge.org/abstract_S136672890200024X

How to cite this article:

Ineke van de Craats, Roeland van Hout and Norbert Corver (2002). The acquisition of possessive HAVE-clauses by Turkish and Moroccan learners of Dutch. Bilingualism: Language and Cognition, 5, pp 147-174 doi:10.1017/S136672890200024X

Request Permissions : $\underline{\text { Click here }}$ 


\title{
The acquisition of possessive HAVE-clauses by Turkish and Moroccan learners of Dutch*

\author{
INEKE VAN DE CRAATS \\ ROELAND VAN HOUT \\ University of Nijmegen \\ NORBERT COR VER \\ Utrecht University
}

\begin{abstract}
This study describes how Turkish and Moroccan adults acquire Dutch possessive clauses in which the verb HAVE expresses the possessive relationship. The acquisition process is explained within the framework of recent generative theory in which HAVE-clauses are assumed to be copular locative constructions. In this theory, predicate inversion of the locative PP and incorporation of the locative $P^{0}$ into a BE-copula are the main characteristics of a possessive HAVE-clause. Assuming that all linguistic knowledge of the L1 is present, L2 learners rely on it from the earliest stages, irrespective of whether this L1 knowledge is parameter-related or not. The results confirm such a "conservation" viewpoint, which accounts for how the possessive relationship is expressed in the earliest stages and why these learners have their languagespecific difficulties in discovering the target HAVE-construction. The results corroborate the conservation effect of both parametrized linguistic knowledge, viz., the strong features triggering predicate inversion, and non-parametrized knowledge, viz., knowledge of syntax, morphology and morphological realization rules, and properties of lexical items.
\end{abstract}

\section{Introduction}

The possessive verb HAVE is not a common feature of the languages of the world. Romance and Germanic languages like French, English and Dutch typically express clausal possession by means of a verb like HAVE. Such a verb is lacking in many other languages, e.g., Russian, Turkish and Semitic languages like (Moroccan) Arabic. In these languages, possession is typically expressed by means of a copular BE-construction showing some locative expression (a PP) denoting the possessor. In this light, it is interesting to describe how speakers of possessive BE-constructions acquire possessive HAVE-constructions, the more so because it is not simply a question of vocabulary learning but of morpho-syntax. Moreover, the domain of possession is more or less a terra incognita in second language research literature. ${ }^{1}$ In this paper, we describe step by step how four Turkish and four Moroccan adults acquire the Dutch possessive HAVE-clause, which is new for them. The description of that acquisition process is the first objective of this paper.

The second objective is to explain the acquisition process. For this purpose, recent insights from

\footnotetext{
* The authors are grateful to the four anonymous reviewers for comments on an earlier version of this paper.

${ }^{1}$ L2 acquisition studies that touch upon some aspects of the possessive relationship are, e.g., Broeder (1992), Parodi, Schwartz and Clahsen (1997) and Van de Craats, Corver and Van Hout (2000).
}

linguistic theory will be used in which both clausal construction types, BE- and HAVE-constructions, derive from the same underlying construction, a locative copular sentence ${ }^{2}$ (e.g. of Lyons, 1968; Clark, 1978; in a generative framework: Freeze, 1992; Kayne, 1993; Den Dikken, 1994; Moro, 1997). The basic idea is that the BE-copular construction is the origin of the HAVE-clause. Two movements, namely, (i) inversion of the locative PP predicate with the subject (the theme of the locative clause) and (ii) incorporation of the locative preposition $\mathrm{P}^{0}$ into the BE-copula, transform the BE-clause into a HAVEclause. These two properties define the core differences in possessive clause constructions between the source and the target languages involved (see Table 1 below, p. 156). However, the parameter values triggering predicate inversion and movement of $\mathrm{P}^{0}$ differ minimally and are of minor importance to characterize the differences between the three languages (see Table 1). Turkish displays predicate inversion and incorporation, and is similar to Dutch in those respects. It differs, however, in the position where the possessor is base generated, visible to the language user by a genitive case marker. Moroccan Arabic differs from Dutch by the fact that incorporation of a preposition $\mathrm{P}^{0}$ into a copular form is not allowed. Moroccan Arabic has found two language-specific solutions for raising the possessor anyhow: (i) headto-head movement of $\mathrm{P}^{0}$ in the present tense and (ii)

\footnotetext{
2 This is unlike Parodi (2000), who considers possessive have a verb with underspecified lexical content.
}

Address for correspondence Ineke van de Craats, Department of Linguistics, University of Nijmegen, P.O. Box 9103, 6500 HD Nijmegen, The Netherlands E-mail: I.v.d.Craats@let.kun.nl or c.d.van.decraats@freeler.nl 
predicate inversion of the $\mathrm{PP}$ including the $\mathrm{P}^{0}$ in the past tense. The learners' task consists of discovering these facts and applying the new knowledge to the new language.

The third objective of this study is to contribute to the ongoing debate on the L2-initial state (cf. Eubank, 1996; Schwartz and Sprouse, 1996; Vainikka and Young-Scholten, 1996). It tackles the question as to whether the L1 morpho-syntactic, but nonparameter-related knowledge is taken as the starting point by L2 learners. If that is the case, the acquisition process must provide evidence for the genitive marking of the possessor in HAVE-clauses (for Turkish learners) and for non-incorporation of the locative preposition (for Moroccan learners).

In this paper, the view is taken in the description and analysis of the acquisition process, that the steady state of the L1 grammar constitutes the starting point of the L2 acquisition process. This amounts to both the Full Transfer/Full Access hypothesis (Schwartz and Sprouse, 1996) and the Conservation Hypothesis (Van de Craats, Corver and Van Hout, 2000). The latter, however, explicitly states that the learners' output cannot show all L1 properties because of a strongly limited L2 vocabulary. With the developing vocabulary, (more) L1 properties related to free and bound functional morphemes become gradually manifest, as we will see in the learners' data where, initially, copular forms and genitive case markers are not found. In the Full Transfer/Full Access hypothesis, absence of such elements can only be explained by full transfer. Such an explanation can be used for the absence of a BEcopula in the case of Moroccan Arabic, or, to some extent, also for the optional realization of the BEcopula in Turkish, but not for the absence of a genitive marker, because realization of a genitive marker is obligatory in Turkish.

The Conservation Hypothesis states that the following (relevant) aspects of linguistic knowledge are conserved at the L2-initial state:

- syntactic knowledge, e.g., parameter settings (strength values, headedness);

- knowledge of morphology and morphological realization rules (e.g., realization of genitive case);

- knowledge of lexical items: formal features (e.g., categorial values) and semantic-conceptual values;

- pragmatic knowledge of information-related grammatical encodings (e.g., the encoding of topic and focus).

As we will see later in the learners' data, morphological realization rules and formal features of lexical items especially are relevant for the expression of the HAVE-clause. In the next section, for instance, it will be argued that incorporation of a locative preposition into a BE-copula can be represented as the spell-out of the formal features: $\mathrm{P}+$ tense + agreement $=$ HAS (heeft in Dutch). The lexical item equivalent of Has in Moroccan Arabic is the locative preposition Eend with the categorial feature $[-\mathrm{N},-\mathrm{V}]$. Conservation of formal features (but not of the phonological matrix Eend) in L2 Dutch, would imply that there is a stage where L2 learners have not yet found an equivalent of the L1 phonological matrix to map on the formal features of the L1. That is to say that they map the formal feature bundle on an empty (ø) phonological matrix. This suggests that, at a later moment, Moroccan learners may map the Dutch phonological matrix heeft on the L1 formal features $[-\mathrm{N},-\mathrm{V}]$. It is evident that conservation of formal features does not play a role when the features of a lexical item are identical in both languages, e.g., for a lexical item like car. It is of crucial importance, however, when formal features differ, as is the case for the possessive verb HAVE (see the section on the acquisition of possessive HAVE-clauses by the Moroccan learners).

In the minimalist approach adopted here, a lexical item including the case morphology or inflectional ending is taken from the lexicon (i.e., numeration) as a unit (cf. Chomsky, 1995). Functional heads do not dominate inflectional morphology, but dominate bundles of features. The morphology associated with lexical heads has to be checked by abstract features dominated by functional heads. The genitive case feature, for instance, can be checked off by a genitive case-assigning feature within the same functional projection. If one takes this viewpoint, bound morphology is no longer a trigger for movement to a position higher in the syntactic tree. Morphology can be acquired independently of movement and separately from its syntactic position. This approach provides an adequate explanation for early learner varieties in which bound and free morphemes are systematically absent despite of the fact that the items to which they are connected figure in a position to which they are raised (in an L1-based grammar).

The minimalist approach adopted assigns a more essential role to vocabulary in L2 acquisition than other approaches on the L2-initial state (Eubank, 1996; Schwartz and Sprouse, 1996; Vainikka and Young-Scholten, 1996). It is through the vocabulary that syntax becomes manifest, both in the L2 learners' output and in the way learners have access to the L2 environmental input. Adult L2 learners seem to distil from the L2 input (i) what is perceptually salient, (ii) what is meaningful and (iii) what is 
pragmatically relevant. These factors determine which lexical elements are understood first and, subsequently, are produced first. Accordingly, three levels (we call them "states") of vocabulary development can be discerned in the utterances of L2 learners (cf. Tables 3 and 5):

- a content word state (CWS)

- a functional word state (FWS), divided into:

- a free functional morpheme state (FFS) in which free functional morphemes emerge, e.g., the locative preposition in the data of Moroccan learners;

- a bound functional morpheme state (BFS) in which bound morphemes emerge, e.g., the spell-out of various formal features as a HAVEcopula.

In this way, two developmental lines will be distinguished in the description of the acquisition of HAVEclauses:

- a lexical development in morphological realization states: CWS, FFS and BFS

- a grammatical development in stages:

- an initial stage in which learners' data are based on L1 syntax and L1 settings of parameters, termed the "conservation" stage;

- a restructuring stage (data based on a syntactic change or a parameter resetting);

- a target state (data based on L2 grammar).

The proposed stages are determined by the parameter settings. These are L1 parameter settings as long as there is no evidence that an L2 learner has changed a specific parameter. Changes in parameter settings can only be observed through the surface data - the learners' L2 expressions - but the underlying system is, of course, established independently of the data. ${ }^{3}$

As the fully fledged grammar of the L1 is assumed to be the starting point of the L2 acquisition process, the next section discusses the basic syntactic properties of possessive HAVE-clauses in Turkish and Moroccan Arabic as source languages and in Dutch as target language. Subsequently, information is provided on the data collection and the subjects. It provides also an overview of the number of HAVErealizations and zero markers we found. The next section focuses on the variants of the Turkish learners and shows the order of emergence. It starts with a

\footnotetext{
3 As the parametric differences between the languages involved are of minor importance for this particular case of acquisition (the parameter settings of Turkish and Dutch do not differ(!); see Table 1), the division in stages cannot give spectacular results. That differs from the acquisition of possessive noun phrases, where parameter resetting plays a much more important role (see van de Craats et al. 2000).
}

basic, descriptive overview of HAVE-clause variants as they occur in the data. Next, an analysis of all relevant variants is presented. The presentation and discussion of the Moroccan data is set up in the same way. In the last section, general conclusions are drawn with regard to the continuation of the L1 system and the restructuring process.

\section{The grammar of possessive HAVE-clauses}

The main purpose of this section is to provide a structural analysis of the possessive HAVE-clause for each of the two source languages and for the target language. The claim that possessive clauses are basically locative copular constructions (e.g., Lyons, 1968; Clark, 1978) is worked out, more particularly, that HAVE and its Dutch equivalent hebben are copulas. The basic idea is that a possessive HAVE-clause is an inverted locative sentence in which the possessor is moved to a sentence-initial position after incorporation of a locative preposition into the BE-copula. This idea goes back to observations on French by Benveniste (1966). Following Freeze (1992), Kayne (1993), and particularly Moro (1997) this phenomenon is explained as a case of predicate inversion. Moro's theory of copular constructions is illustrated by examples from Dutch, Moroccan Arabic and Turkish.

\section{Predicate inversion in locative copular constructions}

Many languages have sentence pairs like the Russian examples in (1) and (2) in which the positions of the thematic arguments, theme and locative, alternate. The first sentence is a locative clause, the second an existential clause.

(1) kniga (theme) byla no stole (locative) book-NOM was-COP.F.3sG on table-LOC "the book was on the table"

(2) na stole (locative) byla kniga (theme)

on table-LOC was-COP.F.3SG book-NOM.F

"there was a book on the table"

A possessive sentence like (3) parallels the construction in (2): the possessor, which occurs in a locative phrase ( $u$ menja "at me-GEN"), precedes the copula (cf. Lyons, 1968; Clark, 1978; Freeze, 1992).
(3) u menja (locative) byla
kniga (theme)
at me-GEN
was-COP.F.3sG book-NOM.F
"I had a book"

Instead of this locative copular construction, languages like French, English and Dutch use a HAVE-construction to express possession at clausal level. The meaning is the same as in (3). French is 
special because it has both a construction with avoir "to have", like in (4a), and a locative construction, like in (4b).

\section{(4) a Paul a une moto "Paul has a motorcycle" \\ $\mathrm{b}$ cette moto est à Paul this motorcycle is at Paul "his motorcycle is Paul's"}

It is an idea that goes back to Benveniste (1966) that the sentence in (4a) is the inverted counterpart of (4b) and that avoir is nothing else but the copula être in which the locative preposition $\grave{a}$ has been incorporated.

According to Moro (1997) and Den Dikken (1994, 1998), the basis of both sentences in (4) is a small clause (SC) like (5a). The copula linking the two elements is the obligatory spell-out of present tense and $3 \mathrm{sg}$, spelled out as est, as in (5b). In (5c), the preposition $a$ moves out of the PP and is incorporated into the BE-copula, spelled out as $a$, in (5c). In (5d) the PP is moved to Spec,IP.

(5)

a $[\mathrm{sc} \text { Subject }[\mathrm{PP} \text { Predicate }]]^{4}$

b [IP [I $\quad$ [SC une moto [ [PP à Paul]]]]

c [IP [I' est $+\grave{a}_{\mathrm{j}}(=\mathrm{a})$ [sc une moto [ $\mathrm{t}_{\mathrm{j}}$ Paul]]]]

d [IP [PP [P Ø] Paul] $]_{i}\left[_{I^{\prime}}\right.$ a [SC une moto $\left.\left.\left.t_{i}\right]\right]\right]$

In a standard copular sentence like (6), the first and the second noun phrase can be inverted

(6) a [DP1 a picture of the wall] was [DP2 the cause of the riot]

b [DP2 the cause of the riot] was [DP1 a picture of the wall]

In a standard analysis (e.g. Haegeman, 1994, p. 600), the first noun phrase is base-generated in Spec,IP. At first sight, the inverse sentence in (6b) fits in the same structural representation. Yet, those two sentences behave differently in several respects, e.g., with regard to extraction and quantification restrictions. Consider the sentences in (7).

(7) a [which riot $]_{j}$ was a picture of the wall $[\mathrm{DP} 2$ the cause of $\left.t_{j}\right]$ ?

b * [ which wall $]_{j}$ was [DP1 a picture of $\left.t_{j}\right]$ the cause of the riot?

As Moro points out, the two sentences in (7) do not behave like sentences containing a transitive verb with a subject and an object. In such sentences, extractions and quantifications (see also Heycock and Kroch, 1996) are possible from the post-verbal

${ }^{4}$ For clarity of explanation, the division of IP into the categories $\mathrm{TP}$ and AgrP is omitted in this and similar examples. object, but not from the subject (see, e.g., Haegeman, 1994). The sentence pair in (7) - which has (6a) as its basis - shows that an element can be extracted from the second (in a position in which objects normally occur), but not from the first DP (in a position where subjects normally occur). However, the pair of sentences in (8) - which has (6b) as its basis - shows that extraction from the second DP is also impossible in (8a).

(8) a * [which wall $]_{\mathrm{j}}$ was [ DP2 the cause of the riot] [DP1 a picture of $\left.t_{j}\right]$ ?

b * [which riot $]_{j}$ was [DP2 the cause of $\left.t_{j}\right]\left[{ }_{D P 1} a\right.$ picture of the wall]?

Why is the "subject-object" asymmetry absent in copular sentences like (8)?

The idea is that the underlying structure of a copular sentence is a verbless clause or Small Clause (cf. Sportiche, 1981; Stowell, 1983). In example (6a), for instance, the second noun phrase, [the cause of the riot], is dominated by a sort of super-projection: the Small Clause (henceforth SC), which contains both noun phrases. The first noun phase, [a picture of the wall], is considered the subject of the SC and the second noun phrase the predicate. Making use of the Subject-inside-VP hypothesis (see, among others, Kitagawa, 1986; Koopman and Sportiche, 1991), the subject of the SC raises to a higher position in a functional projection, e.g., Spec,IP. This is exemplified in (9) for the canonical copular sentence in (6a).

(canonical copular sentence)

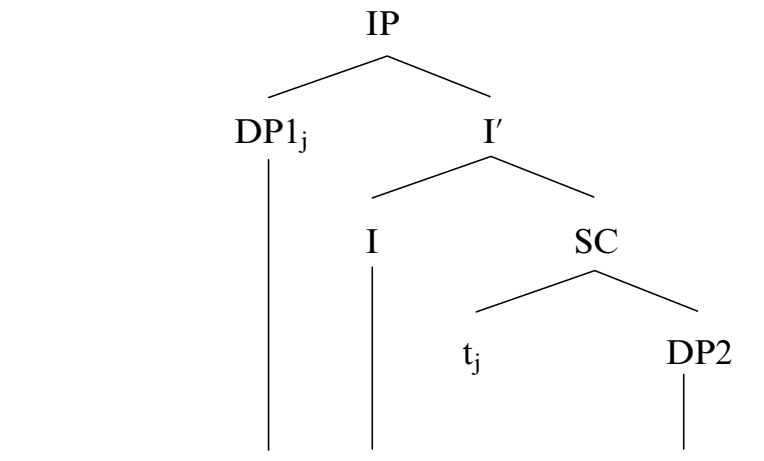

a picture of the riot was the cause of the riot

It is proposed (e.g., Hoekstra and Mulder, 1990; Moro, 1997) that the predicate of the SC (the cause of the riot) can also be raised to Spec, IP. This derivation is represented in (10) (the structural representation of (6b)). As the sentence in (9) exhibits the same subject-object asymmetry as a noncopular sentence, this sentence is considered the canonical copular sentence; and (10), which does not permit 
extraction from either noun phrase, corresponds to the inverse sentence. (inverse copular sentence)

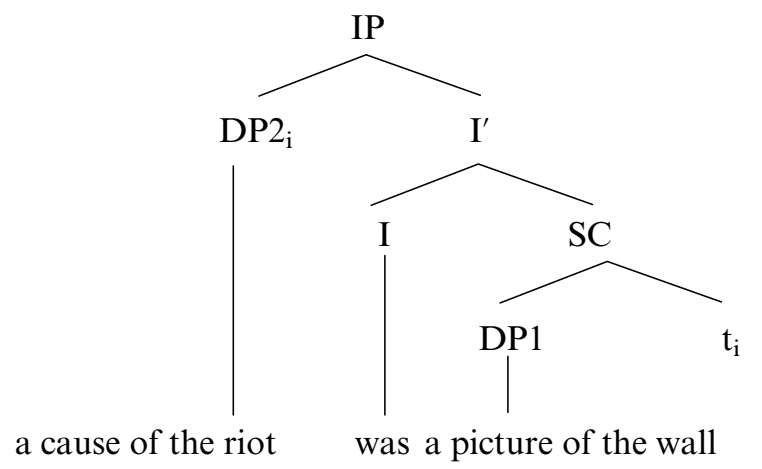

In inverse copular sentences, the postverbal noun phrase (DP1) is in the subject position of the SC. This subject forms an island for extraction (see (8)).

A second characteristic of inverse copular constructions is the obligatory realization of a copula. ${ }^{5}$ As Moro (1990) puts it, "Predicate Inversion triggers the obligatory presence of a copular element in contexts in which a copula would not be required in the absence of Predicate Inversion" (as cited in Den Dikken, 1998, p. 180). Take the sentence pair in (11), drawn from Moro (1997), as an example.

(11) a We consider a picture of the wall (to be) the cause of the riot (straight order)

b We consider the cause of the riot ?(to be) a picture of the wall (inverted order)

The copula in (11a) can be omitted: consider can take either a to-infinitival complement or a common SC. In (11b), where Predicate Inversion has applied, the copula is obligatory. For some native speakers, the absence of the copula in predicate inversion contexts only yields a mildly deviant sentence. That is, the contrast between straight order sentences with a missing copula and inverted order sentences with a missing copula does not seem to be very strong. What may be a relevant factor in the strength of the contrast is the heaviness of the "inverted subject". Compare, for example, the pair of sentences in (11) with the pair in (12).

(12) a I consider Bill (to be) the cause of the riot (straight order)

b I consider the cause of the riot *(to be) Bill (inverted order)

5 Another property is that Predicate Inversion involves A-movement, unlike movement processes like topicalization and whmovement, which are $\mathrm{A}^{\prime}$-movements.
Example (12b), with a missing copula, seems to be more deviant than example (11b), also with the copula being absent. Possibly, (11b) involves the phenomenon of heavy NP-shift. In that case, it is not the nominal predicate the cause of the riot that has undergone (leftward) displacement. Rather, heavy NP-shift has applied to the noun phrase a picture of the wall. In that case, the heavy subject would have been moved rightward across the nominal predicate the cause of the riot. Under a heavy NP-shift analysis (i.e. rightward movement of the small clause subject), the presence of a copular element is not triggered. As shown by the following example, drawn from Chomsky (1981, p. 70), heavy NP shift can be applied to small clause subjects:

(13) I would consider_ intelligent [anyone capable of understanding Godel's completeness proof]

Importantly, in (12), we find a strong contrast. If heavy NP-shift had applied in (12b), the inverted order would always yield an ill-formed output, given the fact that a non-heavy NP cannot be shifted rightward. The well-formedness of the order the cause of the riot to be Bill suggests that heavy NP-shift is not involved here. The contrast in (12b) (i.e., acceptable with to be; unacceptable without to be) must then be due to the presence versus the absence of predicate inversion.

In what follows, this theory of Predicate Inversion is applied to possessive clausal constructions. Summarizing we can state that

- incorporation of a(n abstract) locative element triggers a different spell-out of the copula.

- predicate inversion makes the copula obligatory.

\section{The possessive HAVE-clause in Dutch}

A similar incorporation process to that in French occurs in Dutch, where the verb hebben "to have" is considered an instantiation of zijn "to be" into which an abstract preposition has been incorporated. This process results in the inversion of the prepositional predicate (containing the possessor) and yields a copula consisting of person and number features, a tense feature plus a locative preposition spelled out as a form of hebben. ${ }^{6}$ The derivation proceeds as follows. The preposition P moves out of the PP and is incorporated into the feature bundle in the nearest functional head dominating the $\mathrm{SC}$, in this case

${ }^{6}$ Note that, in this approach, a copula is no longer a lexical primitive, but an overt realization of functional features in I or Agr (see Freeze 1992) or the realization of some functional heads, successively adjoined to each other (see also Den Dikken 1994, 1998)). 
T. This complex is moved to AGR by a <strong> head-related feature on AGR. Such movement fully obeys the Head Movement Constraint (Travis, 1984). The incorporated $\mathrm{P}$ then becomes one of the factors that determine the phonological form of the copula. In Dutch, the entire $[A G R+[T+P]]$ complex is spelled out in AGR as heeft "has" for 3sg. Subsequently, the $\mathrm{PP}$, in which only the possessor DP has remained, is raised to Spec,TP, the nearest projection, higher than SC, and subsequently to Spec,AgrP (attracted by $<$ strong $>$ Spec-related features on $\mathrm{T}$ and AGR. The derivation of the possessive copular hebben-construction is given below, in (14). The possessive clause in (14a) derives from the SC in (14b) and is represented in $(14 \mathrm{c}) .^{7}$

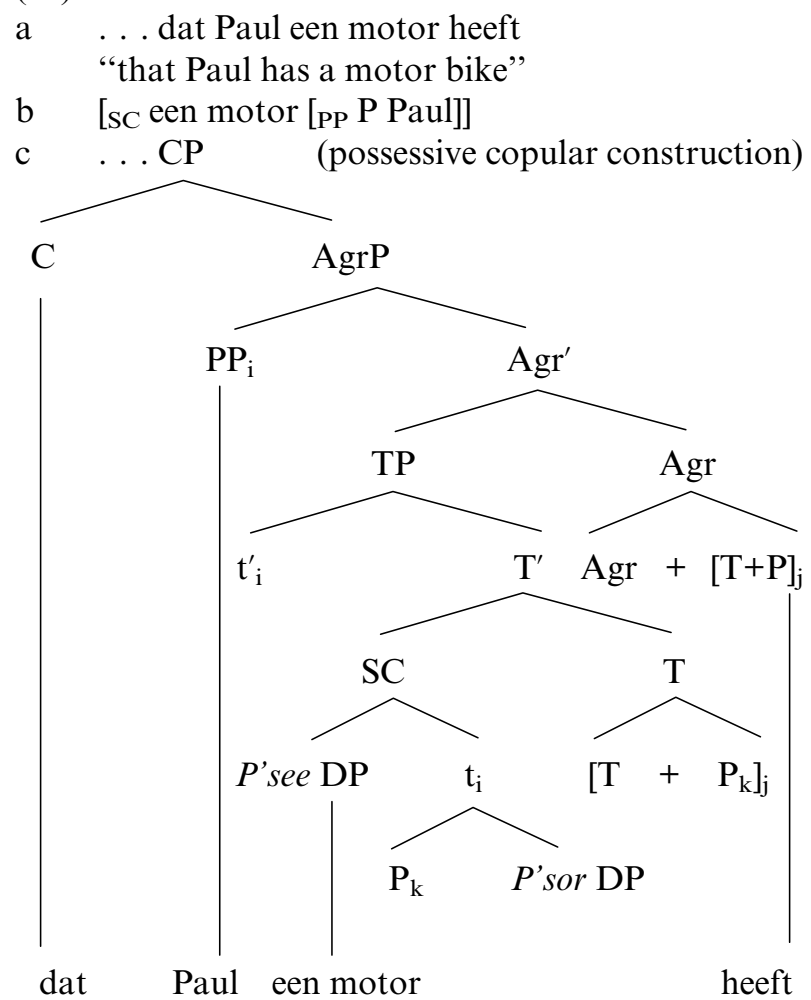

\section{The possessive HAVE-clause in Turkish}

At first sight, a Turkish possessive clause, like the one in (15), is not similar to the possessive clauses discussed before. First, the possessor is marked by a genitive case and, secondly, the locative character of the predicate is not manifest.

\footnotetext{
7 In (7), we take the embedded clause in order to show the basic position of the verb in Dutch that is assumed to be SOV underlyingly. In (14c), P'see = "Possessee" and P'sor = "Possessor".
}

(15) Hitay-in kitab-I var Hitay-GEN book-3sg present "Hitay has a book"

The first question that arises is whether the genitive marked possessor Hitay-in is a locative expression which has inverted with the subject of the SC, kitab-I. If this were the case, the copular form var would be the result of the inversion (i.e., the spell-out of a functional head) as it was the case in Dutch and French. Such an analysis can be represented as in (16).

\section{(16) [IP Hitay-in ${ }_{j}\left[s c\right.$ kitab-I [PP $t_{j}$ ]] var]}

Obvious objections to this analysis are that (i) the "possessive" suffix $-I(3 \mathrm{sg})$, which refers to a relationship with another noun phrase, cannot be licensed ${ }^{8}$ and (ii) the copular spell-out var cannot be the consequence of the inversion of the DP, Hitay-in, marked by genitive case, because the copular form $v a r$ is also found in sentences like (17a) and (17b), in which the DP marked for genitive case and the possessive suffix $-I$ are missing as well. There must be another reason for the spell-out of the copula var. The only element that the sentences in (17) have in common, and that can invert with the subject of the $\mathrm{SC}$, is a phonetically empty locative pronoun (loc.pro). This is an abstract element comparable to the locative that occurs in existential sentences: there in English and er in Dutch. This element is assumed to be present in (17a) and (17b). In (17b), the locative PP ben-de "at me" is adjoined to AgrP but it is not the inverted locative phrase.
a kitap var
book present
"here is a book"
[IP [PP loc. pro] $]_{\mathrm{j}}\left[\mathrm{sC}\right.$ kitap [PP $\left.\left.\mathrm{t}_{\mathrm{j}}\right]\right]$ var]
b ben-de kitap var
I-LOC book present
"I have a book with me"
[IP ben-de [IP [PP loc. pro $]_{j}\left[\mathrm{sC}\right.$ kitap [ [PP $\left.\left.\mathrm{t}_{\mathrm{j}}\right]\right]$
var]]

Consider now the variant in which the genitive marked possessor occurs together with a locative PP, e.g., in (18).
(18) [IP ben-de [IP [PP loc.pro $]_{j}$ [sC Hitay-in I-LOC Hitay-GeN
kitab-I [PP $\left.\mathrm{t}_{\mathrm{j}}\right]$ var]]
book-3SG present
"I have Hitay's book with me"

\footnotetext{
8 An empty pro as the possessor is no alternative because Hitay-in already expresses the possessor and this would violate the theta criterion.
} 
In (18), the copula is obligatorily spelled out because a PP has inverted with the subject of the SC. We can infer from (17a) that the inverted PP is a loc.pro and not an overt PP, as in (17b). The only difference between (17b) and (18) is that the possessor of the book is specified: Hitay-in. The conclusion must be that the possessor, Hitay-in, is not the inverted predicate.

It becomes clear how the structure of the standard possessive clause in Turkish is derived: from an SC with Hitay-in kitab-I as the subject of the SC and a loc.pro (i.e., Ø) as the predicate (see (19)). The existential form var is the spell-out of person and number features (3sG) plus a locative case feature (cf. Freeze, 1992), i.e., [[P+T]+AGR].

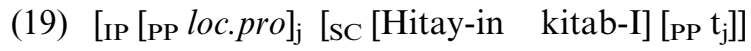
Hitay-GEN book-3sG

var]

present

"Hitay has a book"

Yet, the string Hitay-in kitab-I is not necessarily a single constituent, because clauses in (20) are found, in which a PP occurs between the possessor and the possessee.

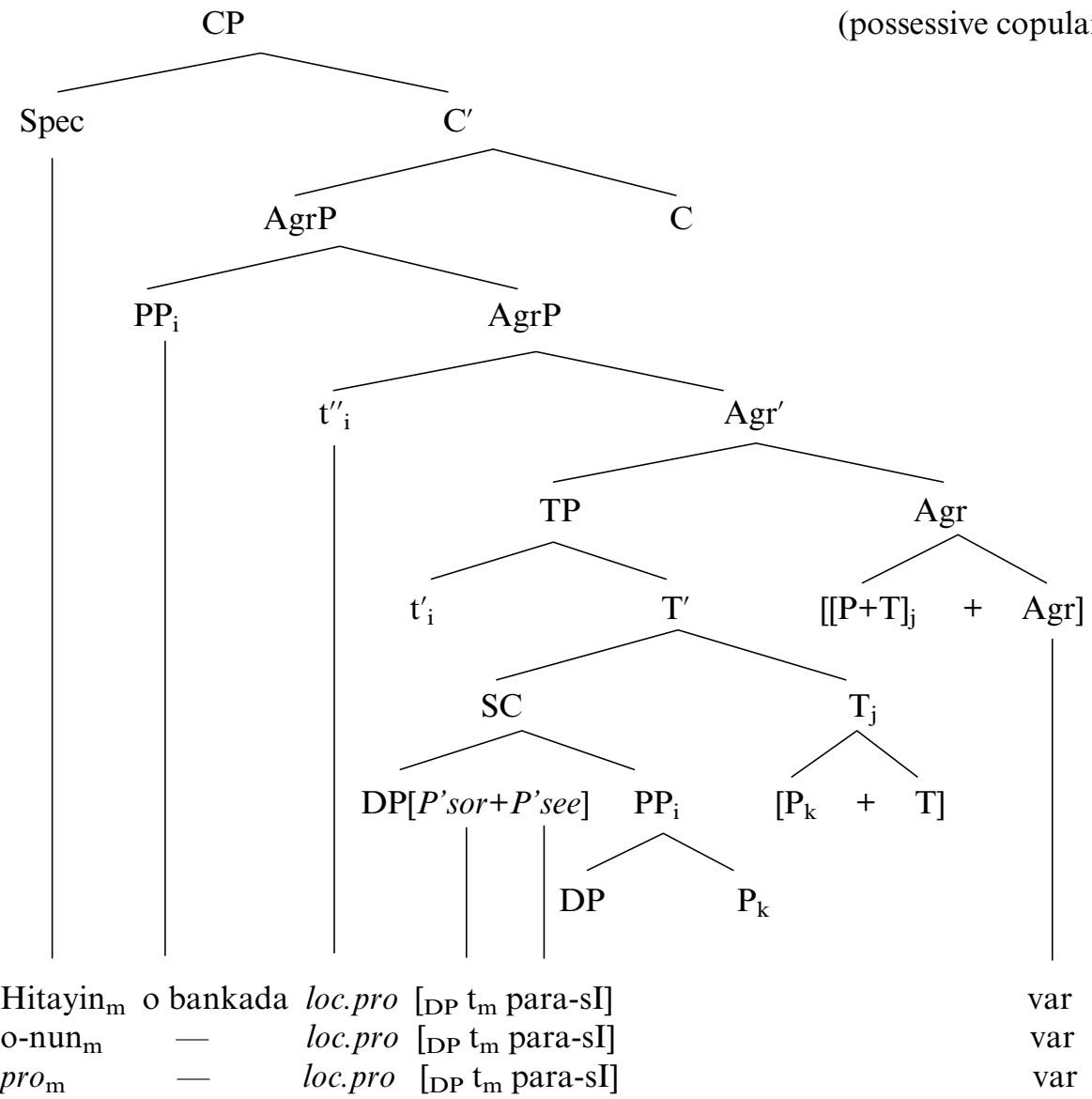

9 Analogously to Hungarian (Szabolcsi 1992). 
1997). In order to get a possessive reading of the clause, this pro moves to the topic position in Spec, CP. Although the possessive clause in Turkish is basically locative, the possessor marked by genitive case is its most salient characteristic.

\section{The possessive HAVE-clause in Moroccan Arabic}

Like Russian (cf. (3)), Moroccan Arabic does not realize a HAVE-variant. Yet, the structure is not a simple case of predicate inversion since present-day Moroccan Arabic displays a considerable variation in the expression of the possessive clause. Consider first the possessive matrix clause in the present tense, (22a), and the past tense, (22b).

(22) a Matrix clause, present tense

Abder, Eend-u dar kbira

Abder at-him house.F big.F

"Abder has a big house"

b Matrix clause, past tense

Abder, kanet Eend-u dar kbira

Abder COP.PAST.3sG.F at-him house.F big.F

"Abder had (aspect: used to have) a big house"

The examples in (22a) and (22b) suggest the same syntactic structure, viz., the inverted PP Eend- $u$ in the Spec-position of the nearest functional projection, higher than the SC. However, the nearest projection is AgrP for (22a), but TP for (22b). This structural difference becomes manifest in negated sentences like (23a) and (23b). The verbal heads in (23a, b) allow circumposition of the negation $m a-\check{s}(i)$, whereas the non-verbal head in (23c) does not. This "real" PP (with a purely locative meaning) is preceded by the entire negative complex. So, it can be concluded that (i) Eend- $u$ in (23a) behaves like a verb, and Eend-na in (23c) like a PP, and that (ii) the syntactic structure in (23a) differs from the structure in (23b).

\section{(23) a Negated present tense clause \\ Abder, ma- Eend-u- š dar \\ Abder not- at-him- NEG.PARTICLE house.F kbira \\ big.F \\ "Abder doesn't have a big house" \\ b Negated past tense clause \\ Abder, ma- kanet- $\quad \check{\text { s }}$ \\ Abder not- COP.3sG.F- NEG. PARTICLE \\ Eend-u dar kbira \\ at-him house.F big.F \\ "Abder did not have a big house" \\ c No sentential negation \\ ma -š Eend-na \\ not -NEG.PARTICLE at-us \\ "not with us, not at our place"}

How is this difference explicable? Following the analysis of negation for Romance languages (e.g., Haegeman and Zanuttini, 1991), we assume that, as ne pas in French, sentential negation in Moroccan

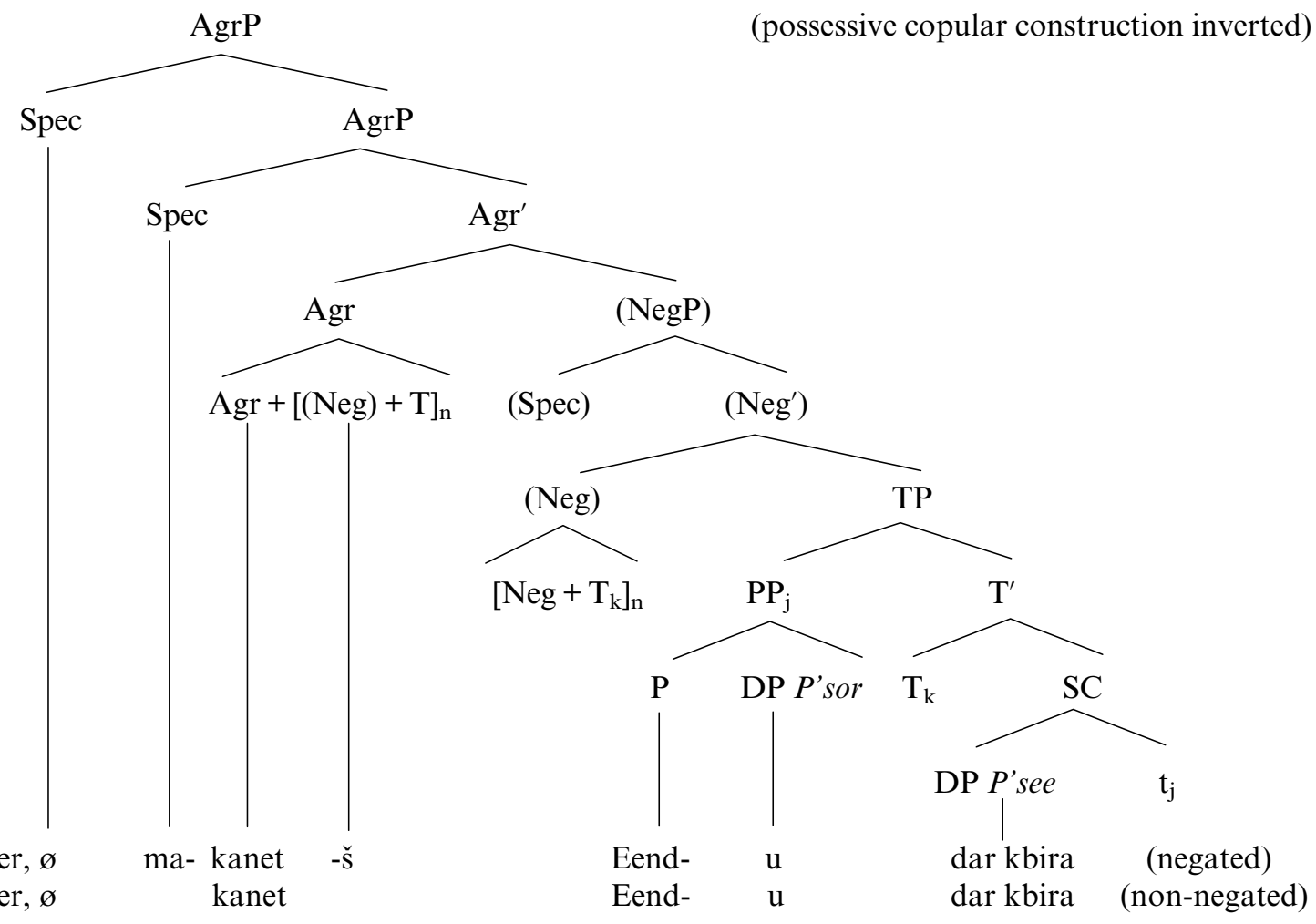


Arabic is expressed by means of a clitic ma- and a negation particle $-\check{s}(i) . M a$ - is a head-like element (NEG head) which cliticizes to AGR and $-\check{s}$ occupies the specifier position of the functional projection $\mathrm{NegP}$, (as is illustrated above in (24)).

In (24a), the past tense copula kanet "was.F" raises by head-to-head movement to the NEG head and is incorporated into NEG, giving rise to the $[\mathrm{NEG}+\mathrm{T}]$ complex ma+kanet. This complex moves to AGR to form the $[\mathrm{AGR}+[\mathrm{NEG}+\mathrm{T}]]$ complex jumping over the second part of the negation, $-\check{s}$, which results in a circumposition of the negation around the verb: $m a-$ kanet-š. Subsequently, the entire PP predicate Eend-u inverts with the subject and moves to Spec,TP. In (24b) the non-negated sentence is represented.

As tense is not expressed in normal copular sentences in Moroccan Arabic, no TP category has to be projected in the clause of (23a). Therefore, the complex head $(\mathrm{P}+$ clitic, Eend-u) is directly moved to NEG by head-to-head movement, where it adjoins to $m a$-. Finally, the latter complex (ma-Eend-u) is moved to the AGR head, which results in ma-Eend- $u$ - $\check{s}$ in (23a). This result is not attained by predicate inversion, but by head-to-head movement. See (25a) below for the representation of this derivation.

Notice that the same head-to-head movement is not possible when the $\mathrm{T}$ head is occupied by the past tense copular form kanet "was.F", which we assume not to permit adjunction of non-clitic elements. In the latter case, the full PP predicate Eend- $u$ inverts with the subject, which results in the negated sentence of (23b) and (24a, b).

It should be emphasized that the full DP possessor, Abder, which the clitic $-u$ in $(25 \mathrm{a}, \mathrm{b})$ refers to, is in a dislocated position, often separated from the matrix clause by an audible pause. This is also the case in embedded sentences even though the full possessor follows the complementizer belli "that". Moroccan Arabic permits dislocated elements adjoined to AgrP, which is evidenced by the embedded sentence pair in $(26 \mathrm{a}, \mathrm{b})$ in which Malika is the subject. So, Abder must be in dislocation not only in (26b), but also in (26a). The syntactic structure is given in (26c).

(26) a kan-Eref belli, Abder, ka-t-Eref -u hetta I know that Abder know -him even Malika

Malika

"I know that even Malika knows Abder"

b kan-Eref belli, Abder, hetta Malika I know that Abder even Malika ka-t-Eref -u knows -him

c ... [CP belli [IP Abder [IP hetta Malika

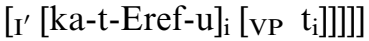

If the full possessor in dislocation is adjoined to AgrP in the embedded clause, it can also be adjoined to AgrP in the matrix clause, though it cannot be

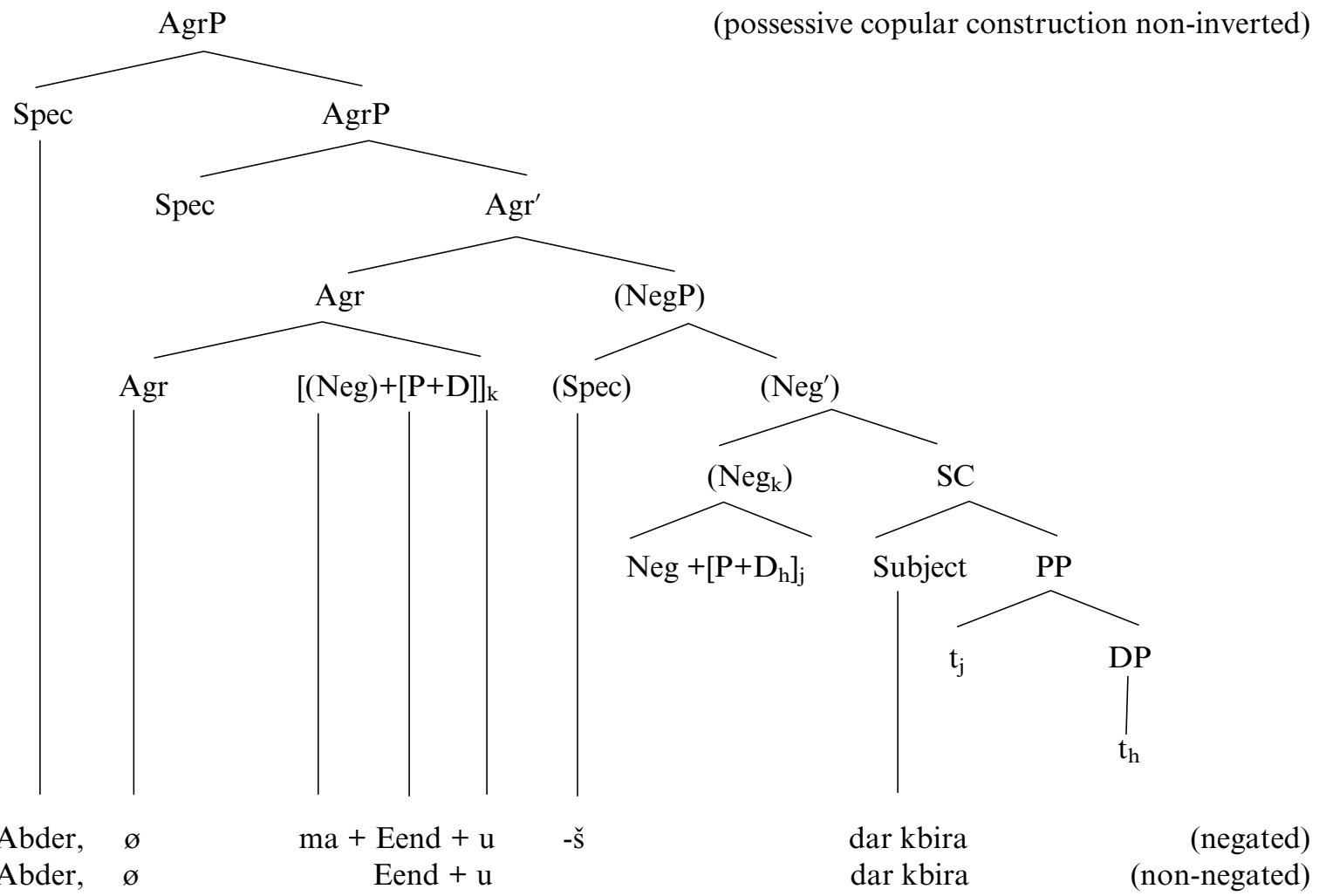


Table 1. Syntactic and morphological properties of possessive clauses (abstracting from the position of the head and $V_{\mathrm{fin}}$-to-C movement); differences between source language and target language are in bold

\begin{tabular}{|c|c|c|c|c|}
\hline & & Dutch & Turkish & Moroccan Arabic \\
\hline 1. & Base position of the possessor & complement of $\mathrm{P}$ & subject of the SC & complement of $\mathrm{P}$ \\
\hline \multirow[t]{3}{*}{2.} & $\begin{array}{l}\text { PP Predicate Inversion } \\
\text { Spec-related feature }[-\mathrm{N},-\mathrm{V}] \\
\text { Attracting PP }\end{array}$ & yes & yes & yes, iff past tense \\
\hline & - on $\mathrm{T}$ & $<$ strong $>$ & $<$ strong $>$ & $<$ strong $>$ \\
\hline & - on Agr & $<$ strong $>$ & $<$ strong $>$ & <weak> \\
\hline \multirow[t]{6}{*}{3.} & $\begin{array}{l}\text { Incorporation of } \mathrm{P} / \mathrm{LOC} \\
\text { head-related feature }[-\mathrm{N},-\mathrm{V}] \\
\text { attracting } \mathrm{P}\end{array}$ & yes $(\mathrm{P})$ & yes (LOC) & no \\
\hline & - on $\mathrm{T}$ & $<$ strong $>$ & $<$ strong $>$ & no TP \\
\hline & - on Agr & $<$ strong $>$ & $<$ strong $>$ & $\begin{array}{l}<\text { strong }>\text {, iff } \mathbf{T P} \\
\text { projection is absent }\end{array}$ \\
\hline & spell-out of copula & & & \\
\hline & - in present tense $3 \mathrm{sg}$ & HEEFT & VAR & no copula (no TP) \\
\hline & - in past tense $3 \mathrm{sg}$ & HAD & VAR-DI & KAN \\
\hline \multirow[t]{3}{*}{4.} & $\begin{array}{l}\text { Surface properties } \\
\text { of the possessor }\end{array}$ & & & \\
\hline & - syntactic position & in Spec, AgrP & in Spec, CP & $\begin{array}{l}\text { dislocated topic: } \\
\text { full possessor DP; } \\
\text { Agr-head (present), } \\
\text { Spec, TP (past) }\end{array}$ \\
\hline & - morphological form & nominative DP & genitive DP & $(\mathrm{P}+)$ post-clitic \\
\hline
\end{tabular}

excluded that the dislocated possessor is adjoined to $\mathrm{CP}$. What is more important, is that the possessor + Eend-clitic behaves like subject + verb, except for a subject-verb agreement. ${ }^{10}$

\section{Overview}

This theoretical section is closed off by summarizing in what respects the three languages differ from each other and in what respects they are similar. On the basis of the analyses presented in this section, we present an overview in Table 1 . We abstract here from the position of the head and from V-to-C movement as applied in the well known V2 construction (see Haegeman, 1994). As both phenomena are not directly related to the expression of possession in the clause, we will keep them separated from the possessive construction in the discussion of the data.

10 Caubet (1993, p. 51) considers the construction by means of Eend + clitic as "une tournure prépositionnelle qui est utilisée comme un prédicat de possession. La verbalisation de cette expression de localisation est très avancée".
In Table 1 , the row marked 1 provides information on the position in which the possessor is base generated. The rows marked 2 provide information on the application of Predicate Inversion, i.e., the overtness of the movements of the predicate to Spec,TP and Spec,AgrP. Rows 3 concern information on the movement of the locative feature ( $\mathrm{P}$ or locative case) and the way it changes the spell-out of the copula after incorporation. In the last row, the surface position of the possessor is characterized by its syntactic position after movement and its morphological form.

From the perspective of conservation of L1 grammatical knowledge, it is crucial to indicate precisely what are the differences between source and target language, and what has to be learned by Moroccan and Turkish learners of Dutch. We have indicated this schematically in the three colums of Table 1 by marking in bold the differences between the source language and the target language. As this table shows, the three languages are almost identical with respect to structure; the present tense clause in Moroccan Arabic is most deviant. A superficial but 
important similarity is that in all three languages, the possessive clause presents itself in the order possessor-possessee although the syntactic structure is considerably different.

\section{Subjects, data collection and data}

The data used for this study come from the European Science Foundation (ESF) corpus. These data were collected within the framework of the ESF Program on Second Language Acquisition by Adult Immigrants (for design and elicitation techniques see Perdue, 1993). This project was set up as a longitudinal and cross-linguistic multiple case study. In this article, the focus is on the acquisition of Dutch by four Moroccan immigrants (age 17-24): Fatima (FAT), Mohamed (MOH), HassanK (HASK) and HassanM (HASM), and four Turkish immigrants: Mahmut (MAH), Ergün (ERG), Osman (OSM) and Abdullah (ABD) in the Dutch part of the project. The eight informants learning Dutch outside the classroom were followed during almost two and a half years. The period of investigation was divided into three cycles of nine sessions, 27 recording sessions totally, one session a month. In each cycle, the same elicitation tasks were repeated (role playing, interviews and film-retelling tasks). At the first session, the informants had been living in the Netherlands for 7 to 12 months. They had a very low proficiency in Dutch, were monolingual, and had a limited level of education. Several elicitation tasks were repeated in each cycle, such as interviews, roleplaying and film-retelling tasks.

The corpus was exhaustively scanned for clausal possessive constructions of the HAVE-type. Due to the fact that HAVE-clauses typically display the order Possessor-Possessee it was possible to separate them from clausal constructions of the type deze motor is van Paul (this motorcycle is of Paul; "this motorcycle is Paul's"), which typically display the opposite order. The order is an important classification characteristic because the "linking" copula (hebben) is either overtly realized, or is a zero marker in data of beginning L2 learners. Possessive clauses with a zero marker can be distinguished from two-word possessive nominal phrases by the fact that, in the first case, the complete sentence consists of two lexical items: the possessor and the possessee, whereas the twoword possessive noun phrase is only a phrase and typically forms a larger sentence. The context was decisive in problematic cases. Let us give an example. The learner's utterance ik fiets ("I bike") may be a noun phrase when it is an answer to the question who's bike is that? In other cases, it probably is a HAVE-clause with the meaning "I have a bike". In this way all HAVE-clauses were selected, also those missing a form of the copula have.

Before presenting an analysis of the HAVE-clauses produced by the Turkish and Moroccan learners, a distribution of the two types of HAVE-clauses (with

Table 2. Distribution of HAVE-types in clausal possessive constructions of four Turkish and four Moroccan learners; $Y=$ possessor and $X=$ possessee

\begin{tabular}{lcclcc}
\hline \hline Turkish informants & YX hebben & YX zero marker & Moroccan informants & YX hebben & YX zero marker \\
\hline $\begin{array}{l}\text { Mahmut } \\
\text { cycle 1 }\end{array}$ & - & 66 & Fatima & & \\
cycle 2 & 6 & 79 & cycle 1 & 9 & 57 \\
cycle 3 & 10 & 109 & cycle 2 & 27 & 67 \\
Ergün & & & Mohamed 3 & 22 \\
cycle 1 & 29 & 28 & cycle 1 & & \\
cycle 2 & 92 & 31 & cycle 2 & 44 & 18 \\
cycle 3 & 105 & 22 & cycle 3 & 140 & 12 \\
Abdullah & & HassanK & 159 & 1 \\
cycle 1 & 60 & 12 & cycle 1 & 84 & 2 \\
cycle 2 & 78 & 14 & cycle 2 & 168 & 8 \\
cycle 3 & 37 & 5 & cycle 3 & 82 & 6 \\
Osman & & HassanM & & \\
cycle 1 & 29 & 45 & cycle 1 & 59 & 8 \\
cycle 2 & 10 & cycle 2 & 146 & 3 \\
cycle 3 & 88 & 15 & cycle 3 & 138 & - \\
\hline \hline
\end{tabular}



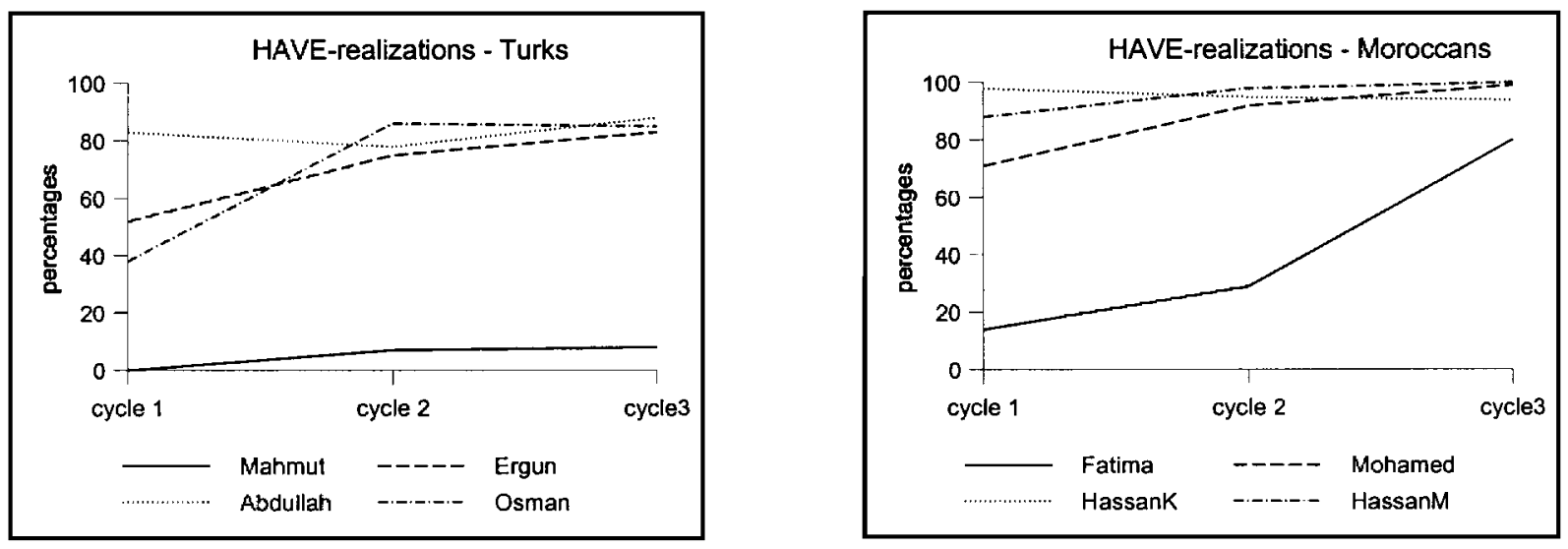

Figure 1. Percentages of possessive clauses in which hebben is realized, produced by Turkish and Moroccan learners.

and without the realization of hebben) is given as they occurred in the raw data. The raw scores are given in Table 2, next the developmental aspect of HAVErealizations over the three cycles is given in the graphs of Figure 1.

The raw scores of Table 2 and the graphs in Figure 1 show that three out of the eight informants scored above $80 \%$ realizations of hebben from the beginning of the data collection. Three other informants progressed considerably after the first cycle, one informant (Fatima) did so after the second cycle, and only one Turkish informant, Mahmut, did not produce more than $10 \%$ realizations of hebben at the end of the data collection. Relying on these raw scores, one gets the impression (i) that the Moroccan learners in this project progress faster than the Turkish learners, despite the fact that the possessive clause in their L1 differs more from the target construction, and (ii) that most informants in this project acquire the HAVE-clause rather easily (compared to the acquisition of nominal possessive constructions described in Van de Craats et al. (2000)). The above data will be reconsidered after the structural analysis of the learners' variants, first of the Turkish learners, then of the Moroccan learners.

\section{The acquisition of possessive HAVE-clauses by the Turkish learners}

\section{Description and analysis}

On the basis of the comparison between the properties of source languages and target language given in Table 1, a simple list can be made of what has to be learned by a Turkish learner of Dutch:

- The syntactic knowledge that a possessor is generated within the PP as a complement of $\mathrm{P}$ (no genitive case involved).
- The morphological rule that spells out the $[\mathrm{AGR}+[\mathrm{T}+\mathrm{P}]]$ complex as a form of hebben.

The steps taken by L2 learners to acquire this knowledge are represented in Table 3. This table provides two types of information. First, it gives an overview of the types of possessive HAVE-variants found. Second, it indicates which variants appear at what developmental stage (viz., a stage when parameter settings are involved, a state when vocabulary is involved; see also the introduction). Each type of possessive HAVE-variant is exemplified by a token. It represents the first or one of the first occurrences of the possessive variant in the corpus. The rightmost column indicates the speaker and the recording session. (Information about frequency of occurrences can be found in Table 4.) Table 3 is descriptive in providing the range of variants and interpretive in the assignment of these variants to developmental stages. The structural analyses motivate this assignment.

\section{Conservation stage}

In the earliest stages of acquisition, all learners produce expressions consisting of two nouns, as in (27a), which can be extended as in (27b). ${ }^{11}$

(27) a vader winkel

$$
\begin{aligned}
& \text { b [mijn vader] Turkse winkel } \\
& \text { my father Turkish shop } \\
& \text { "my father has a Turkish shop" }
\end{aligned}
$$

ABD-1

Sentences like those in (27), consisting of bare noun phrases, are characteristic of early learner varieties, both in L1 and L2 acquisition. Such possessive clauses are similar to utterances produced by Dutch, German and French children, and by German-Italian bilingual children, cf. the examples in (28).

\footnotetext{
11 The first of these two nouns is a DP, the second noun is below the level of DP (e.g., a QP or an NP). For reasons of simplicity the first noun is indicated by DP, the second by NP.
} 
Table 3. Variants of the possessive clause found in the developmental stages of the four Turkish learners; possessor DP is indicated by square brackets

\begin{tabular}{|c|c|c|}
\hline Stage & Example & Subject code \\
\hline \multicolumn{3}{|l|}{ 1. Conservation stage } \\
\hline \multicolumn{3}{|l|}{ a. Content Word state (CWS) } \\
\hline \multirow[t]{4}{*}{$-[\mathrm{DP}]+\mathrm{NP}+\varnothing$} & [vader] winkel & \multirow[t]{2}{*}{ ABD-1 } \\
\hline & father shop/"father has a shop" & \\
\hline & [mijn vader] Turkse winkel & \multirow[t]{2}{*}{ ABD-1 } \\
\hline & my father Turkish shop/“my father has a Turkish shop" & \\
\hline \multirow{2}{*}{$-[$ poss. pronoun] $+\mathrm{NP}+\varnothing$} & {$[m i j n]$ drie broer } & \multirow[t]{2}{*}{ ABD- 6} \\
\hline & my three brother/“I have three brothers", & \\
\hline \multicolumn{3}{|l|}{ b. Functional Word state (FWS) } \\
\hline \multirow[t]{4}{*}{$-[\mathrm{DP}]+\mathrm{NP}+$ clause-final hebben } & [Sevgil] vrienden hebben & \multirow[t]{2}{*}{ OSM-7 } \\
\hline & Sevgi friends have/“Sevgi has a boyfriend” & \\
\hline & {$[($ pro $)]$ eentje jongen hebben } & \multirow[t]{2}{*}{ OSM-5 } \\
\hline & (he) one boy have/“he has a son" & \\
\hline \multirow{2}{*}{$-[$ poss.pron.] $+\mathrm{NP}+$ hebben } & [mijn] veel vrienden hebben & \multirow[t]{2}{*}{ OSM-7 } \\
\hline & my many friends have/“I have many friends” & \\
\hline \multicolumn{3}{|l|}{ VAN } \\
\hline \multirow[t]{4}{*}{$-[$ van-poss.pron. $]+\mathrm{NP}+\varnothing$} & [die van mij] auto & \multirow[t]{2}{*}{ MAH-9 } \\
\hline & that of me car/"I (stressed) have a car" & \\
\hline & [van onze] geen stadium (=stadion) & \multirow[t]{2}{*}{ ERG-17 } \\
\hline & of our no stadium/“we don't have a stadium" & \\
\hline \multirow[t]{2}{*}{$-[$ van-poss.pron.] $+\mathrm{NP}+$ hebben } & [van ons] ook zo thuis hebben & \multirow[t]{2}{*}{ ERG-18 } \\
\hline & of us also such home have/“we have also such a house" & \\
\hline \multirow[t]{2}{*}{$-[\operatorname{van}-\mathrm{DP}]+\mathrm{NP}(+h e b b e n / \varnothing)$} & [van een mens] veel schapen & \multirow[t]{2}{*}{ ABD-13 } \\
\hline & of a human being many sheep/“someone has many sheep" & \\
\hline \multicolumn{3}{|l|}{ 2. Target state } \\
\hline \multirow[t]{2}{*}{ - clause-final inflect. hebben } & {$[($ pro $)]$ vier aas heeft } & \multirow[t]{2}{*}{ OSM-17 } \\
\hline & (he) four aces has/“he has four aces" & \\
\hline \multirow[t]{2}{*}{ - no correct agreement } & als $[\mathrm{jij}]$ garage heeft & \multirow[t]{2}{*}{ ERG-18 } \\
\hline & if you garage have/"if you have a garage", & \\
\hline \multirow[t]{2}{*}{ - Fully correct target construction } & [hij] heeft een brief & \multirow[t]{2}{*}{ OSM-27 } \\
\hline & he has a letter/"he has a letter" & \\
\hline
\end{tabular}

(28) a ikke ook auto

(Laura 2;0) I also car

"I have also a car"

(Childes, corpus Van Kampen)

b anche Giulia caminica blau also Guilia shirt blue

(Taeschner 1983)

(bilingual child 2;6)

"Gulia has also a blue shirt"

Merely on the basis of how these noun phrases manifest themselves, one cannot decide what the syntactic structure is: a bare VP, a small clause, or a fully-fledged structure with an inverted (loc.pro) pre- dicate. One might claim that those possessive clauses are part of a Minimal Default Grammar (cf. Roeper, 1999 ) or of a Basic Variety (cf. Klein and Perdue, 1997). If the fully-fledged L1 structure is supposed to be conserved in L2 acquisition, as claimed both by the Full Transfer/Full Access hypothesis and the Conservation hypothesis, one needs to analyze those early data on the basis of a complete L1 syntactic structure. How can we defend the controversial claims of a complete L1 structure? In the first place, using available knowledge sources is not a less economical principle than not using them. In the second place, the assumption of a complete L1 structure makes sense when we reconstruct the course of the 
acquisition stages backwards. The underlying L1 structure becomes manifest in later developmental stages, when distinctive morphological elements manifest themselves, viz., genitive case markers on the "subject" (i.e., the possessor) of the copula hebben. If the $\mathrm{L} 1$ grammar works at time B (when L1 properties appear), we suppose that the L1 grammar works under the same conditions at time A (when bare nouns appear) immediately preceding time B. In this way, we reconstruct the invisible parts of the L1 grammar at work at a previous time A. In the third place, there is evidence of an underlying L1 grammar in the bare noun phrase period for possessive noun phrases. In nominal possessive constructions, both orders are allowed in Dutch as exemplified in (29).

(29) a kaart Wauwa
card Laura

(Sarah $1 ; 10)$

"Laura's card"

(Childes, corpus Van Kampen)

(target Dutch: de kaart van Laura)

b Nienke huis

(Sarah 2;0)

Nienke house

(Childes, corpus Van Kampen)

"Nienke's house"

(target Dutch: Nienke's huis)

Although the Turkish learners in the project were exposed to this L2 input they only used the first type in early stages and the Moroccan learners exposed to the same L2 input, only used the second type, each language group showing their L1 order (see Van de Craats et al., 2000). When L2 learners base themselves on the L1 structure for possessive noun phrases, they will do the same for possessive clauses.

Reasoning in this way and applying the grammar of Turkish for the clause in (27), we assume that the sentence in (27b) has a small clause structure with an inverted phonetically empty PP (as in Turkish; cf. (21)), and a phonetically empty I head because the specific morpheme realization state (FWS), in which functional features are being realized, has not yet been reached. Accordingly, the sentence in (27b) is represented in (30).

(30) $\left[\mathrm{CP}[\text { mijn vader }]_{\mathrm{m}}\left[\mathrm{IP}[\text { loc.pro }]_{\mathrm{j}}\left[\mathrm{SC}\left[\mathrm{DP} \mathrm{t}_{\mathrm{m}}\right.\right.\right.\right.$ Turkse winkel] $\left.\left.\left.\mathrm{t}_{\mathrm{j}}\right]\right] \mathrm{P}+\mathrm{I}=\varnothing\right]$

The next examples display more L1 elements. In (30) mijn "my" was a constituent with vader, but that is probably not the case in (31).

(31) mijn^ drie broer $^{12}$

ABD-6

my three brother

12 The diacritic symbol ${ }^{\wedge}$ marks a rising contour in combination with a slight pause.
This string might be a possessive noun phrase with the meaning "my three brothers", but given the fact that we are dealing with an entire sentence here, it cannot simply be a possessive noun phrase. If an L1 structural basis is adopted, this string can have the clausal reading represented in (32). ${ }^{13}$

(32) $\left[_{\mathrm{CP}} \operatorname{mijn}_{\mathrm{m}} \wedge \text { IIP }_{\mathrm{PP}} \text { loc.pro }\right]_{\mathrm{i}}\left[_{\mathrm{SC}}\right.$ [DP $_{\mathrm{m}}$ my

drie broer] $t_{i}$ ] I] C]

ABD-6

three brother

"I have three brothers"

Important reasons for adopting the clausal possessive construction rather than a nominal one are: (i) it fits better in the discourse context, (ii) contrary to Dutch as the L2, the possessor in an L1-based clausal possessive is marked for genitive and (iii) a kind of segmentation is observed after the possessor marked by a slight pause and a rising contour. Moreover, such constructions are found in utterances of other learners than Abdullah, e.g.:

- constructions, produced by Mahmut, in which the genitive-marked possessor (mijn) is separated from its possessee by particles such as niks ("nothing, not"), or ook ("also"); see (26);

- constructions, produced by Osman, in which the genitive-marked possessor ( $m i j n$ ) co-occurs with the infinitival hebben; see (32);

- constructions produced Mahmut, Ergün and Abdullah himself, in which the genitive-marked possessor is preceded by van; see the examples in (35).

The adverbial elements in (33), ook and the negator niet/niks, act as separators, just as in Turkish.

$$
\begin{aligned}
& \text { a mijn niks andere familie мAн-9 } \\
& \text { I-GEN nothing other family } \\
& \text { "I don't have any relatives" } \\
& \left.{ }_{\mathrm{C} P} \text { mijn }_{\mathrm{m}} \text { [IP }_{\text {[PP loc.pro }}\right]_{\mathrm{i}}\left[_{\mathrm{NegP}} \text { niks [sC } \text { [DP }_{\mathrm{m}}\right. \\
& \text { andere familie] } t_{i} \text { ] Neg] I] C] } \\
& \text { b mijn ook auto MAH-15 } \\
& \text { I-GEN also car } \\
& \text { "I have also a car" } \\
& \text { [CP } \left.\text { mijn }_{\mathrm{m}} \text { [IP [PP loc.pro] }\right]_{\mathrm{i}} \text { [ook [sC [DP } \mathrm{t}_{\mathrm{m}} \\
& \text { auto] } \mathrm{t}_{\mathrm{i}} \text { ]] I] C] }
\end{aligned}
$$

In (33), Mahmut does not use the nominative form

13 Similar constructions, in which the subject is marked by genitive case, is found in data produced by English children, e.g., (i) but not by Dutch children. If it were an effect of learning Dutch, Dutch children would do the same as Moroccan L2 learners. Neither of these groups does so.

(i) my did it (Emily 2;0)

(Hamburger 1980, cited in Powers \& Musolino 1997) 
$i k$, which he already knows, but the genitive-bearing pronoun mijn.

We now pass to the next morpheme realization state characterized as FWS. The two morpheme realization states are taken together for the Turkish learners, because realization of a copula relates to both states (notice that it is a spell-out of the features tense, person, number and locative (BFS) as a free morpheme (FFS)). The features constituting the copula var "present" are obligatorily spelled out in Turkish. So, it is not surprising that the "root" form hebben ${ }^{14}$ emerges as an equivalent of var. Such an early appearance of hebben at the end of the clause is exemplified by Osman in (34a), represented in (34b).

(34) a mijn veel vrienden hebben

OSM- 7 my many friends have "I have many friends"

b $\quad\left[\mathrm{CP} \quad \operatorname{mijn}_{\mathrm{m}}\left[\mathrm{IP}[\text { loc.pro }]_{\mathrm{j}}\left[\mathrm{sc}\left[\mathrm{DP} \mathrm{t}_{\mathrm{m}}\right.\right.\right.\right.$ veel vrienden] $\left.t_{j}\right] \mathrm{I}+$ loc $=$ hebben]]

In fact, there is no structural difference between (34b), in which the formal features in the I head are spelled out as hebben, and the Turkish equivalent, in which the spell-out is var. In the L2 realization of the functional heads in I (hebben), person and number are not overtly marked just as in the Turkish form var. ${ }^{15}$

In line with the above analysis, we assume that the clause in (35a), which occurs in the same recording session as (34a), has the same structure. A more target-like analysis as in (33b) is possible. In this analysis, the possessor Sevgi is base-generated as the complement of P; the PP containing the possessor Sevgi is subsequently moved to Spec,IP as a result of overt Predicate Inversion, as represented in (35b). This analysis may be possible, however, not plausible in our view because of (34). The analysis in (35c) is preferable.

(35) a Sevgi vrienden hebben

OSM-7

Sevgi friends have

"Sevgi has a boyfriend"

${ }^{14}$ In principle. any other form of hebben would be equally likely here but the non-finite form is more plausible as Turkish learners often start the acquisition of verb with "full forms".

15 The similarity between the properties of L2 item hebben and the L1 item var manifests itself in existential constructions, e.g., in (i), and with an inflected form of hebben (3SG) in (ii). Notice that the position of the existential hebben/heeft has become targetlike in (ii), but not yet in (i). This does not play a role for the spell-out of hebben.

(i) $\left[\mathrm{IP}_{[\mathrm{PP}} \text { loc.pro }\right]_{\mathrm{i}}\left[\mathrm{sC}[\mathrm{DP}\right.$ veel mensen $\left.] \mathrm{t}_{\mathrm{i}}\right] \mathrm{P}+\mathrm{I}=$ hebben $]$ OSM-7 many people have

"there are many people"

(ii) [IP daar [IP [PP loc.pro $]_{\mathrm{i}}\left[\mathrm{II}^{*} \mathrm{P}+\mathrm{I}(3 \mathrm{SG})=\right.$ heeft $[\mathrm{SC}$ [DP geen pils] there has no beer
$\left.\left.\left.\left.\mathrm{t}_{\mathrm{i}}\right]\right]\right]\right]$

"there is no beer over there" b [IP [pP Sevgi $]_{j}\left[\right.$ sC [DP vrienden] $\left.\mathrm{t}_{\mathrm{j}}\right]$ $\mathrm{I}+\mathrm{P}=$ hebben]

c $\quad\left[\mathrm{CP} \mathrm{Sevgi}_{\mathrm{m}}\left[\mathrm{IIP}_{\mathrm{P}}[\text { loc. pro }]_{\mathrm{j}}\left[\mathrm{sC}\left[\mathrm{DP} \mathrm{t}_{\mathrm{m}}\right.\right.\right.\right.$ veel vrienden] $\left.\mathrm{t}_{\mathrm{j}}\right] \mathrm{I}+\mathrm{LOC}=$ hebben $\left.]\right]$

In (34) and (35), the possessor was expressed by a pronoun or a full noun. The examples in (36) show that the possessor pronoun can be dropped, if the possessor is topical and the topic is continued (an L1 based rule; see Kornfilt, 1997). This pro-drop phenomenon is observable irrespective of the fact whether the formal features are already spelled out as a copular form (36b), or not, (36a).

$$
\begin{aligned}
& \text { CWS: (pro) eentje fiets } \varnothing \quad \text { OSM-3 } \\
& 1 \mathrm{SG} \text { one.DIM bicycle } \\
& \text { "I have a bicycle" } \\
& \text { [CP } \text { pro }_{\mathrm{m}}\left[{ } _ { \mathrm { IP } } [ \text { loc.pro } ] _ { \mathrm { i } } \left[\mathrm { SC } \left[\mathrm{DP} \mathrm{t}_{\mathrm{m}}\right.\right.\right. \text { eentje fiets] } \\
& \left.\left.\left.\mathrm{t}_{\mathrm{i}}\right] \mathrm{P}+\mathrm{I}=\varnothing\right] \mathrm{C}\right] \\
& \text { b FWS: (pro) eentje jongen hebben osM-5 } \\
& \text { 3SG one.DIM boy have } \\
& \text { "he has a son" } \\
& \text { [CP }_{\text {pro }} \text { [IP }_{\text {II }}[\text { loc.pro }]_{\mathrm{i}}\left[_ { \mathrm { SC } } \left[\mathrm{DP}_{\mathrm{m}} \mathrm{t}_{\mathrm{m}}\right.\right. \text { eentje } \\
& \text { jongen] } \mathrm{t}_{\mathrm{i}} \text { ] P + I = hebben] } \mathrm{C} \text { ] }
\end{aligned}
$$

Before reaching the target state, some learners show a variant like the clauses in $(37 a-c)$, in which the possessor is preceded by the genitive marker van "of". It is striking that pronominal possessors preceded by van, $(37 \mathrm{a}, \mathrm{b})$, emerge earlier in the development process than full noun possessors, (37c). In this respect, they reflect the developmental order of the nominal possessive constructions which shows strings such as van mijn broer "of my brother" before van Paul broer (of Paul brother; "Paul's brother") (Van de Craats et al. 2000).

(37) a [die van mij] auto $^{16}$

MAH-9

that of my car

"I (stressed) have a car"

[CP [die van mij] $]_{\mathrm{m}}\left[\mathrm{IP}[\text { loc.pro }]_{\mathrm{i}}\left[\mathrm{SC}\left[\mathrm{DP} \mathrm{t}_{\mathrm{m}}\right.\right.\right.$ auto] $\left.\left.\left.\mathrm{t}_{\mathrm{i}}\right] \mathrm{I}+\mathrm{P}=\varnothing\right] \mathrm{C}\right]$

b [van ons] ook zo thuis hebben ERG-18 of us also such home have "we also (want to) have such a house" [CP $[\text { van ons }]_{\mathrm{m}}$ [IP $[\text { loc.pro }]_{\mathrm{i}}\left[\right.$ ook [sC [DP $\mathrm{t}_{\mathrm{m}} \mathrm{zo}$ thuis] $\left.\mathrm{t}_{\mathrm{i}}\right] \mathrm{I}+\mathrm{P}=$ hebben] $\left.\mathrm{C}\right]$

c [van een mens] veel schapen ABD-13 of a human being many sheep "someone has many sheep" [CP $[\text { van een mens }]_{\mathrm{m}}\left[\text { IIP }_{\text {[loc.pro }}\right]_{\mathrm{i}}\left[\mathrm{sC}\left[\mathrm{DP}_{\mathrm{m}} \mathrm{t}_{\mathrm{m}}\right.\right.$ veel schapen] $\left.\left.\left.\mathrm{t}_{\mathrm{i}}\right] \mathrm{I}+\mathrm{P}=\varnothing\right] \mathrm{C}\right]$

16 One might interpret the presence of die as a way of encoding the property of emphasis. lexical realization of the possessive pronominal implies emphasis in Turkish (see also Kornfilt 1997, p. 284). 
Constructions of the variant in (37) clearly display the genitive-marked possessor, which is characteristic of the underlying L1 structure. One may object that the above possessive clauses have the same structure as in Moroccan Arabic, in which the entire PP is inverted, and that van is a locative preposition, an alternative of the Dutch preposition aan or voor "to". Of course, this possibility cannot be excluded completely. If we consider the last example in (37), there is no spell-out of the copula, and, therefore one might propose that the entire PP van een mens has been inverted with the possessee and is moved to Spec,IP. In such a case, van should be interpreted as a locative preposition, which is not implausible if this were a string uttered by Ergün who, typically, overgeneralizes the use of van. For Abdullah, however, this is less plausible because (i) he did not show such overgeneralization of van and (ii) he already used to spell out the functional heads in I as a form of hebben, and (iii) Turkish learners are used to incorporating the locative feature but not to spelling it out. Moreover, just the fact that the possessor DP does not figure in Spec,IP explains the systematic lack of agreement between the possessor and hebben, and the occurrence of the genitive-marked DP, which is no longer found as soon as hebben is replaced by an inflected form. When inflection of the verb hebben emerges, the possessor seems to have become a subject, and can no longer be case marked by a genitive. This implies that there are no instances of a possessor marked by genitive case agreeing with an inflected form of the "root" form hebben. (See Osman's results in Table 4.) For Ergün, the situation is different from Osman's. Consider the clause in (38). This is a telling example for an important shift in Ergün's learner's grammar, which looks like a step backwards at first sight.

(38) ik heb ook // van mijn ook zak I have also // of mine also bag "I also have a bag"

\section{Chunks}

In (38), Ergün seems able to construct a possessive clause by using hebben. He even uses an inflected form of hebben, but produces a self-correction in the wrong direction: he changes a correct form $(i k h e b)$ into an L1-based form, in which the pronominal possessor is genitive case marked by van. This is not an error, nor the remainder of a previous stage, but it is just the beginning of a new stage in which the chunk $[i k-h e b]$ is analyzed. Interestingly, all instantiations of the verb hebben that occur before recording session 17 are $i k$ heb or the "root" form hebben in clause-final position. ${ }^{17}$ The invariable character of the string $i k$ heb makes it plausible that we are dealing here with a chunk [ik-heb]. This chunk is only used if the possessor is $1 \mathrm{SG}$; if the possessor is a $2 \mathrm{SG}$ or 3sG, Ergün has other solutions: (i) drop the pronominal and use the invariable form hebben, in (39a), or (ii) use the DP + NP combination, in (39b).

$$
\begin{aligned}
& \text { a (pro) NP + hebben } \\
& \text { (pro) frikandel hebben? } \\
& \text { you sausage have } \\
& \text { "do you want to have a sausage?" } \\
& \text { b DP + NP + } \varnothing^{18} \\
& \text { mijn vriend twee diploma } \\
& \text { my friend two diploma } \\
& \text { "my friend has two diplomas" }
\end{aligned}
$$

ERG-6

ERG-11

Such chunks are common, when the examples in (40) show up.

(40) a

$$
\begin{aligned}
& \text { a van onze geen stadium } \\
& \text { of our.INFL no stadium } \\
& \text { "we do not have a stadium" } \\
& \text { [CP } \left.[\text { van onze }]_{\mathrm{m}} \text { [IP [loc.pro }\right]_{\mathrm{i}}\left[\mathrm { sC } \left[\mathrm{DP} \mathrm{t}_{\mathrm{m}}\right.\right. \text { geen } \\
& \text { stadium] } \left.\left.\left.\mathrm{t}_{\mathrm{i}}\right] \mathrm{P}+\mathrm{I}=\varnothing\right] \mathrm{C}\right] \\
& \mathrm{b} \text { van ons ook zo thuis hebben ERG-18 } \\
& \text { of us also such home have } \\
& \text { "if we also had such a house" } \\
& \text { [CP }[\text { van ons }]_{\mathrm{m}} \text { [IP }[\text { loc.pro }]_{\mathrm{i}}\left[\mathrm { ook } \left[\mathrm { sC } \left[{ }_{\mathrm{DP}} \mathrm{t}_{\mathrm{m}} \mathrm{zo}\right.\right.\right. \\
& \text { thuis] } \mathrm{t}_{\mathrm{i}} \text { ] } \mathrm{P}+\mathrm{I}=\text { hebben] } \mathrm{C} \text { ] }
\end{aligned}
$$

The above examples illustrate the conservative character of Ergün's clauses. In $(40 \mathrm{a}, \mathrm{b})$ he uses the possessive pronoun van ons/onze because it is the possessor moved out of the DP (SC-internal). Together with the constructions in (40), other forms of hebben appear, e.g., in (41).
(41) als jij garage heeft (target form: hebt) ERG-18 if you garage have
"if you have a garage"

At the beginning of cycle 3 , the analysis of the chunk is continued. Now, we find the clause in (38) and similar examples. Those are still found in session 25 , together with target strings like wij hebben "we have" and zij heeft "she has". We may conclude from this (i) that Ergün did not use any target stage constructions before session 19, (ii) that he was still producing conserved possessive clauses until session 25 and (iii) that a period of overlap between conservation and target constructions had started in session 18 with the emergence of variable forms of hebben. What exactly chunks and fully analyzed forms are can only be decided by approximation. It can be

\footnotetext{
17 Except for one example in session 9.

18 See footnote 11 for the difference between DP and NP.
} 
stated, however, that HAVE-constructions from session 26 onwards are target constructions, given that possessors marked by genitive case no longer occur.

Mahmut followed the developmental path taken by Ergün. He also started by using chunks. The chunk that emerged first is [ik-heb], which was used in addition to the sentence-final uninflected form hebben. During the last cycle, a second chunk emerged, [heb-ik], evidenced by the double use of $i k$ in $(42 a, b)$. This chunk formation became clear when Mahmut produced the following clauses:
a ik zo probleem [heb-ik]
I such problem have-I
"I have such problems"
b ik [heb-ik] anders niks
I have-I other nothing
"I have nothing else"
c (pro) [heb-ik] niet part-time
I have-I not part-time
"I do not have part-time work"
MAH-24
MAH-24
MAH-25

\section{Target state}

After the necessary morphological changes have taken place within a fully L1-based structure, the syntactic knowledge is acquired that in Dutch the possessor is base-generated within the locative PP. By means of this linguistic knowledge, target constructions can be made. Note that for the notion of the target state, we abstract from the general properties of the clause. This implies that target state constructions are characterized by an inflected form of hebben and a possessor in the subject form. It was abstracted from (i) the position of the inflected verb, (ii) subject drop and (iii) the lack of subject-verb agreement. Thus, the clauses in (43) are considered to be target variants. This will be taken into account when the number of learners' target variants is computed in the next section.

(43) a (pro) vier aas heeft
he four aces has
"he has four aces"
[IP [PP pro $]_{\mathrm{i}}[\mathrm{sc}$ [DP vier aas $\left.] \mathrm{t}_{\mathrm{i}}\right] \mathrm{P}+\mathrm{I}=$ heeft $]$
b als jij garage heeft (target form: hebt)
if you garage has-3SG
"if you have a garage"

\section{Results}

After the analysis of the various possessive variants, the questions should be answered as to (i) how many occurrences of each variant are found in the learners' production data, and (ii) to what extent these four learners attain target knowledge of the HAVE-construction. Table 4 (in relation to Table 3) provides the answers to those questions. In Table 4, the same distinctions as in Table 3 are made; and two more distinctions, viz., (i) for Mahmut and Ergün the strings ik-heb "I have" are counted separately because they are considered unanalyzed wholes and (ii) the pronominal possessors are distinguished from the full DP possessors because it seems that the latter lag behind in the development of the possessive clause.

The first result that can be inferred from Table 4 is that all learners used forms of hebben, but only three of them attained target knowledge of HAVEpossessives; two out of four informants (if we leave out the unique example produced by Ergün in cycle 1) did so even within the first cycle. The two fast learners - Abdullah and Osman - almost skipped FWS constructions within the conservation stage: for them, the spell-out of functional heads lead to an inflected form of the target copula hebben. Particularly, Ergün still applied the L1 morphological realization rule in the last cycle: he was still using possessive forms (e.g., mijn and van mijn) instead of subject forms.

Another conspicuous outcome is that full DP possessors occur more often in combination with a zero-realization of hebben than pronominal possessors (see conservation stage, CWS). This tendency is decreasing toward the end of cycle 3 , but is still observable for all learners in the last cycle. In cycle 3 , Osman and Abdullah, being the best learners, do not exhibit any zero realization of the copula in combination with a pronominal possessor (see conservation stage: poss.pronoun $+\mathrm{NP}+\varnothing$ and FWS-VAN), but in the case of a full DP possessor, they use as many zero realizations as overt HAVE-realizations (Abdullah), or even more (Osman). Only when we consider the results of the last sessions (these are sessions 26 and 27 for Osman, and 25 for Abdullah), a $100 \%$ score is attained; in other words, no more zero realizations are found.

Evidently, the acquisition process proceeds within the pronominal construction and the full DP construction follows this development toward the target construction. That is not surprising because a pronominal possessor provides more reliable information on its case than a full DP possessor. Only a pronominal possessor, clearly marked as a nominative, can convince the learner that he should reject the genitive marking of the possessor in HAVE-constructions, and that a subject-verb agreement is required instead.

Although the copula hebben emerged in very early stages already, not all forms of hebben turned out to 
Table 4. Distribution of the variants of possessive HAVE-clauses produced by the four Turkish learners over developmental stages

\begin{tabular}{|c|c|c|c|c|c|c|c|c|c|c|c|c|}
\hline \multirow[b]{2}{*}{ Cycles } & \multicolumn{3}{|c|}{ Mahmut } & \multicolumn{3}{|c|}{ Ergün } & \multicolumn{3}{|c|}{ Abdullah } & \multicolumn{3}{|c|}{ Osman } \\
\hline & 1 & 2 & 3 & 1 & 2 & 3 & 1 & 2 & 3 & 1 & 2 & 3 \\
\hline \multicolumn{13}{|l|}{ 1. Conservation stage } \\
\hline \multicolumn{13}{|l|}{ CWS } \\
\hline$-\mathrm{DP}+\mathrm{NP}+\varnothing$ & 64 & 74 & 108 & 26 & 23 & 8 & 11 & 10 & 5 & 45 & 16 & 15 \\
\hline- poss.pron. $+\mathrm{NP}+\varnothing$ & 1 & 4 & - & - & 4 & 6 & 1 & - & - & - & 1 & - \\
\hline \multicolumn{13}{|l|}{ FWS } \\
\hline$-\mathrm{DP}+\mathrm{NP}+$ hebben & - & 2 & 3 & 11 & 2 & 7 & 1 & 4 & 1 & 14 & 10 & 1 \\
\hline- chunk $+\mathrm{NP}$ & - & 4 & 7 & 17 & 85 & 52 & - & - & - & - & - & - \\
\hline- poss.pron. $+\mathrm{NP}+$ hebben & - & - & - & - & - & - & - & - & - & 6 & 1 & - \\
\hline \multicolumn{13}{|l|}{ VAN } \\
\hline- van.poss.pron. $+\mathrm{NP}+\varnothing$ & 1 & 1 & 1 & 2 & 4 & 7 & - & 3 & - & - & - & - \\
\hline - van.poss.pron $+\mathrm{NP}+$ hebben & - & - & - & - & 1 & - & - & - & - & - & - & - \\
\hline- van-DP+NP+ø & - & - & - & - & - & 1 & - & 1 & - & - & - & - \\
\hline
\end{tabular}

\section{Target state}

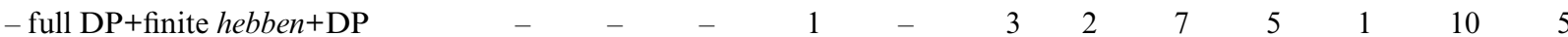

$\begin{array}{llllllllllllllll}- \text { pronominal+finite hebben+DP } & - & - & - & - & & 4 & 43 & 57 & 67 & 31 & 8 & 82 & 82\end{array}$

\begin{tabular}{llllllllllllll}
\hline Total & 66 & 85 & 119 & 57 & 123 & 127 & 72 & 92 & 42 & 74 & 120 & 103 \\
\hline \hline
\end{tabular}
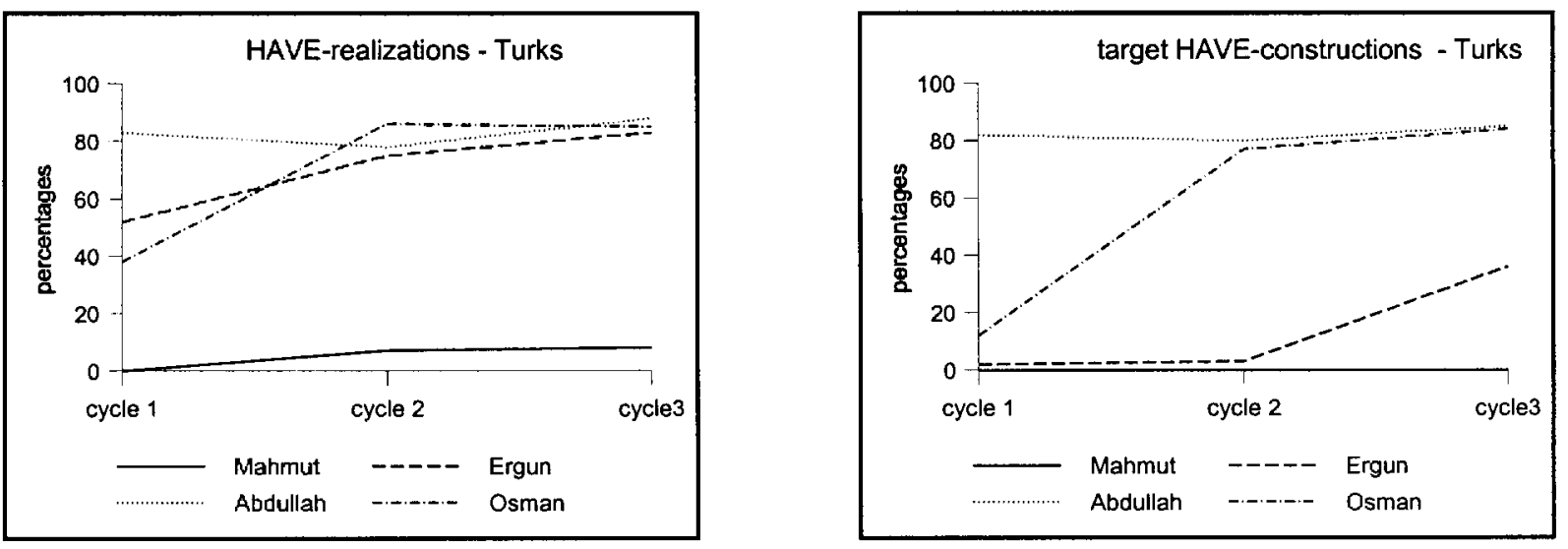

Figure 2. Results on the acquisition of HAVE-constructions produced by four Turkish learners: left for all realizations of hebben; right for all target constructions.

be morphologically analyzed. Ergün is a good example of such a behavior: he was using $i k$-heb, later replaced by hebben (sentence-final) or by a genitive marked possessor van mijn (see (39) and (40)).

To give a clear picture of the acquisition results and the effect of data interpretation, the percentages of HAVE-realization before and after data interpretation are compared in Figure 2. The difference in the results of the four informants in the left graph and in the right graph is accounted for by the occurrence of chunks and the morphological development that must take place. These phenomena cannot be observed at the surface of the HAVE-possessive clauses for Osman and Ergün (in the left graph), only on the basis of data interpretation, when all forms of hebben are mutually compared. This does not hold for Abdullah. For Mahmut, there is not a big difference between raw scores and interpreted scores: he had not abandoned the conservation stage at the end of the data collection and no target construction has been found (his scores are not visible in the right graph). 


\section{The acquisition of possessive HAVE-clauses by the Moroccan learners}

\section{Description and analysis}

From the comparisons between the properties of source language and target language in Table 1, the following list of what has to be learned by Moroccan learners of Dutch is made.

\section{Resetting of:}

- Spec-related feature $[-\mathrm{N},-\mathrm{V}]$ on AGR: resetting to a $<$ strong $>$ value.

\section{Acquisition of:}

- the syntactic knowledge that both a full noun possessor and a pronominal possessor are generated as a complement of $\mathrm{P}$;

- the syntactic knowledge that P can be incorporated into a BE-copula;

- the projection of the category TP in present tense clauses;

- the morphological rule that spells out the $[\mathrm{AGR}+[\mathrm{T}+\mathrm{P}]]$ complex as a form of hebben.

The above list is larger than the list for the Turkish learners. It implies a resetting aspect with regard to parameter values, and an acquisition aspect with regard to syntactic, morphological and lexical aspects. Would a larger list of learning items also mean that the acquisition process will be longer?

Before presenting the analysis of the variants occurring in the production data of the Moroccan informants, an overview of the variants is given in Table 5 (comparable to Table 3 for the Turkish data). In this table, three morphological states are distinguished (two for the Turkish data). Unlike what we saw in the development of the Turkish learners, a short restructuring stage is distinguished. Also, syntactic changes which are not parameterrelated shifts, e.g., the projection of a TP category in the present tense, are classified under this restructuring stage although, strictly speaking, there is no parametric change. The number of tokens of each of these types is given in Table 7.

\section{Conservation stage}

In the earliest stage of acquisition, all Moroccan learners, just like the Turkish learners, seem to produce clausal expressions consisting of two noun phrases, as in (44). Most of the Moroccan learners have left this stage at the beginning of the data collection, except for Fatima (as we will see in Table 7).
(44) a Nominal possessor

mijn vrouw ook klein huis

MOH-6

my wife also small house

"my wife also has a small house"

b Pronominal possessor

ik klein winkel

FAT-3

I small shop

"I have a small shop"

The variants of Moroccan and Turkish learners are similar in the earliest stage of development from a first, superficial point of view. According to the Conservation hypothesis, though, their underlying structures differ. The Moroccan utterances in (44) have a Moroccan Arabic L1-based structure, while a similar utterance from a Turkish learner has a Turkish L1 structure (compare (44a) to (27a)). Adopting an L1 underlying structure, we propose (45) as the syntactic structure for $(44 a, b)$, in which the possessor mijn vrouw is in a dislocated position because it is followed by a pause separated from the possessee klein huis, and by the particle ook "also", presumably adjoined to the SC. See (25) for a similar syntactic structure in the form of a tree diagram.

$$
\begin{aligned}
\text { a } & {\left[\text { AgrP mijn vrouw } \left[{ } _ { \text { AgrP } } \left[\text { Agr' }^{\prime} \text { AGR }+\right.\right.\right.} \\
& {[\mathrm{P}+\text { pro }]_{j} } \\
\text { b } & {\left.\left.\left[\text { ook }\left[\mathrm{sC} \text { klein huis } \mathrm{t}_{\mathrm{j}}\right]\right]\right]\right] } \\
& \text { ik AGR }+[\mathrm{P}+\text { pro }]_{\mathrm{j}} \text { klein winkel }
\end{aligned}
$$

It is assumed that (45b) has the same syntactic structure as (45a), although the pronominal possessor $i k$ may suggest that $i k$ is the object pronominal cliticizing on $\mathrm{P}$ (phonetically empty here). ${ }^{19}$ This might also be suggested by the fact that there is no clearly observable pause after the pronominal. Such a pause, however, is often not audible. The reason why the analysis in (45b) is to be preferred is that, in a subsequent morpheme realization state (FFS), a preposition emerges between the possessor and the possessee, e.g., in (46). In (46a), a pronominal possessor precedes the preposition, in (46b) a nominal possessor.

$$
\begin{aligned}
& \text { a ik met klein winkel } \\
& \text { I with small shop } \\
& \text { "I had a small shop" } \\
& \text { [AgrP ik [AgrP }\left[\text { Agr' }^{\prime}\left[\mathrm{AGR}+[\mathrm{met}+\text { pro }]_{j}\right]\right. \\
& \text { [sC klein winkel } \left.t_{j}\right] \text { ]]] } \\
& \text { b Fatiha Mustafa Khilifiye met andere } \\
& \text { Fatiha Mustafa Khilifiye with other } \\
& \text { moeder } \\
& \text { mother } \\
& \text { FAT-3 } \\
& \text { FAT- } 12
\end{aligned}
$$


Table 5. Variants of the possessive clause found in the developmental stages of the four Moroccan learners

\begin{tabular}{|c|c|c|c|}
\hline & Stage & Example & Subject code \\
\hline \multicolumn{4}{|c|}{ 1. Conservation stage } \\
\hline \multirow[t]{6}{*}{ a. } & \multirow{6}{*}{$\begin{array}{l}\text { Content Word State (CWS) } \\
- \text { DP+DP }\end{array}$} & ik klein winkel & FAT-3 \\
\hline & & I small shop/“I had a small shop" & \\
\hline & & nou (pro) geen huis & FAT-6 \\
\hline & & now no house/"now you do not have a house" & \\
\hline & & mijn vrouw ook klein huis & мOH-6 \\
\hline & & my wife also small house/"my wife also has a small house" & \\
\hline \multirow[t]{6}{*}{ b. } & Free functional state (FFS) & ik [met pro] klein winkel & FAT -3 \\
\hline & & I with small shop/“I had a small shop" & \\
\hline & & Fatiha Mustafa [met pro] ander moeder & FAT-12 \\
\hline & & F. M. with other mother/"F and M have another mother" & \\
\hline & - prepositional heeft & ik heeft $47 \mathrm{jaar}$ & FAT -9 \\
\hline & & I has 47 year/“I am 47” & \\
\hline \multirow[t]{5}{*}{ c. } & Bound Functional state (BFS) & & \\
\hline & - past tense: was & ik was ruzie met leraar & HASK-12 \\
\hline & & I was trouble with teacher/“I had troubles with the teacher" & \\
\hline & - past tense: was heeft & die was heeft een huis & HASK-18 \\
\hline & & that was has a house/“he had a house" & \\
\hline \multirow[t]{7}{*}{2.} & Restructuring stage & & \\
\hline & $-[P P]+D P$ & [met die man] naam semsar & FAT-7 \\
\hline & & with that man name semsar/"that man is called semsar" & \\
\hline & $-[\mathrm{PP}]+i s+\mathrm{DP}$ & [van de boer] is meer autoos & HASK-27 \\
\hline & & of the farmer is more cars/"the farmer has more cars" & \\
\hline & $-[\mathrm{PP}]+h e e f t+\mathrm{DP}$ & [met Soumiya] heeft veel pijn & HASM-23 \\
\hline & & with Soumiya has much pain/“S. has a lot of pain” & \\
\hline \multirow[t]{4}{*}{3.} & Target state & & \\
\hline & - present tense: heeft & $\begin{array}{l}\text { hij heeft geen geld } \\
\text { "he has no money", }\end{array}$ & FAT-27 \\
\hline & - past tense: had & ik had ruzie met leraar & HASK-19 \\
\hline & & "I had troubles with the teacher" & \\
\hline
\end{tabular}

"Fatiha Mustafa and Khilifiye have another mother"

[AgrP Fatiha .... [AgrP $\left[\right.$ Agr' $\left[\mathrm{AGR}+[\mathrm{met}+\mathrm{pro}]_{j}\right]$ [sc andere moeder $\left.\left.\left.t_{j}\right]\right]\right]$

In $(46 \mathrm{a}, \mathrm{b})$ the preposition met (i.e., $[\mathrm{P}+\mathrm{D}])$ adjoins to the feature complex in AGR, yielding the $[\mathrm{AGR}+[\mathrm{P}+\mathrm{D}]]-$ complex without predicate inversion, just as in the source language. ${ }^{20}$

20 Of course, other analyses of these clauses are possible, but seem implausible in the light of the Conservation hypothesis. The sentences in (46) for instance, may be considered SC constructions in which is the preposition met, and klein winkellandere moeder the complement of $\mathrm{P}$, as is represented below:

(i) a $\left[\mathrm{SC} \mathrm{ik}_{\mathrm{i}}[\mathrm{PP}\right.$ met [DP klein winkel]]]
Now we follow more closely the developmental path of two learners, Fatima and HassanK, because they reveal precisely what is the structural basis of their L2 expressions at different points of the L2 acquisition process. Fatima, as the slowest learner, showed the details of a very early phase. HassanK revealed the details of a later developmental phase. Consider first the three examples of Fatima in (47).

b [SC Fatiha, Mustafa, Khilifiye [PP met [DP andere moeder]]] Although there is no formal objection against this analysis, it is not likely in the light of the L1 structural basis and in the light of the intended meaning. This structure does not have a possessive reading associated with it. 
(47)

a mijn moeder heeft twee kinder FAT-5 my mother has.PREs.3sG two children "my mother has two children"

b ik heeft $\quad 47$ jaar $^{21}$ FAT-9 I have.PRES.3sG 47 year "I am 47"

c jullie heeft 'n bus you.PLUR has.PRES.3sG a van "you have a van"

Although (47a) seems a perfect example of a target construction, we reject the interpretation that heeft is a conjugated verb because the supposed finite verb heeft is not inflected at all, i.e., does not display overt agreement with the subject (in $(47 b, c)$ ). The very first forms of hebben, heb-1sG, emerged in sessions 4 and 5 , they were probably imitations since, after these first examples, Fatima did not show any variation in this supposed finite form, and she continually used heeft for the first person singular (e.g., in (47b)), and for any plural form as well (47c). In addition to this lack of agreement, one can observe an alternation between met and heeft during ten months, until heeft outweighs met, as shown below in (48).

(48) Fatima: met-heb/heeft alternation in the cycles 1 and 2 session 3 :

$\begin{array}{rll}\text { 3: } & \text { met } & \\ \text { 4: } & & \text { heb } \\ \text { 5: } & & \text { heb/heeft } \\ \text { 6: } & \text { met } & \\ \text { 7: } & & \text { met/heeft } \\ 8: & \text { met } & \\ \text { 9: } & & \text { heeft } \\ \text { 10: } & \text { met } & \\ \text { 12: } & & \text { heeft } \\ \text { 13: } & \text { met } & \text { heeft } \\ \text { 14 and ff: } & & \text { heeft }\end{array}$

In this time span, heeft has the same meaning as met. It even is the equivalent of met, and simply has the conserved value of a preposition $[-\mathrm{N},-\mathrm{V}]$. This is not surprising if we assume that the learner is trying to match the L2 linear string Abder heeft een boek "Abder has a book" with the string Abder Eend-u ktab (Abder with-him book) in the L1. Identifying heeft as the equivalent of Eend- $u$ is obvious then. Therefore, we consider the time before session 14 as a

21 In Moroccan Arabic one's age is also expressed by means of a HAVE-construction, e.g.,

(i) Eend -i tmeneya $u$ rešrin sana with/at -me twenty and eight year "I am twenty eight",

So, the use of hebben in (47b) is a case of $\mathrm{L} 1$ conservation. pure conservation stage. Only in cycle 3 , heb $(1 \mathrm{sG})$ is systematically distinguished from heeft $(3 \mathrm{sG})$.

Another striking L1 property manifests itself in HassanK's data when he attempts to produce HAVEclauses in the past tense. Recall that it was argued earlier that Moroccan Arabic shows different syntactic structures for HAVE-clauses in the present and in the past tense. As we have seen, in the present tense the P+clitic (Eend+clitic) can move to AGR (no predicate inversion), while this movement is blocked when the past tense is spelled out, so that the past tense consists of a form of kan "be" followed by $\mathrm{P}+$ clitic, being the result of predicate inversion. If learners base themselves on the structure of their L1, possessive clauses like (49a, b) will be evident.

(49) a ik was ruzie met leraar

HASK-11 I was quarrel with teacher (target: ik had ruzie)

"I had a quarrel with the teacher"

b hij was verkering met een meisje HASK-11 he was relationship with a girl

$$
\text { (target: hij had verkering) }
$$

"he was walking out with a girl"

c hij heeft twee kinderen

HASK-11 he has two children

Although HassanK seems able to produce target possessive clauses in the present tense in session 11 (e.g., in (49c)), L1 properties appear for the past tense. First, clauses appear in which the past tense of hebben is represented by a simple past tense of the $\mathrm{BE}-$ copula (cf. (49a, b): was). This emergence of was is already reminiscent of the L1 grammar of Moroccan Arabic, but we even assume that the copula was figures in the same syntactic position as the Moroccan Arabic copula kan (be.COP.PAST.MASC) instead of a finite form of hebben that would be expected. The speaker, HassanK, does not yet seem to consider heeft a verb which can be marked for the past tense. Instead he expresses the past tense through the copular form was. Note that $(49 a, b)$ is a fully conserved structure in which $\mathrm{P}$ is phonetically empty and so is the resumptive pronoun (3SG) which refers to a dislocated noun phrase. Just like in Moroccan Arabic, the Spec-related feature on Agr has a $<$ weak $>$ value, with the result that the PP is not moved upwards within overt syntax. This becomes manifest somewhat later, cf. (50), when the copula was is followed by heeft. In Moroccan Arabic, a $\mathrm{P}+$ clitic (Eend+clitic) would be expected in the same syntactic position, viz., in Spec,TP. Just like Fatima in (48), HassanK seems to assume that heeft is equivalent to Eend+clitic as it normally emerges in AGR, but here, the AGR head is filled by the copula was. In such constructions, it becomes clear that 
(51)
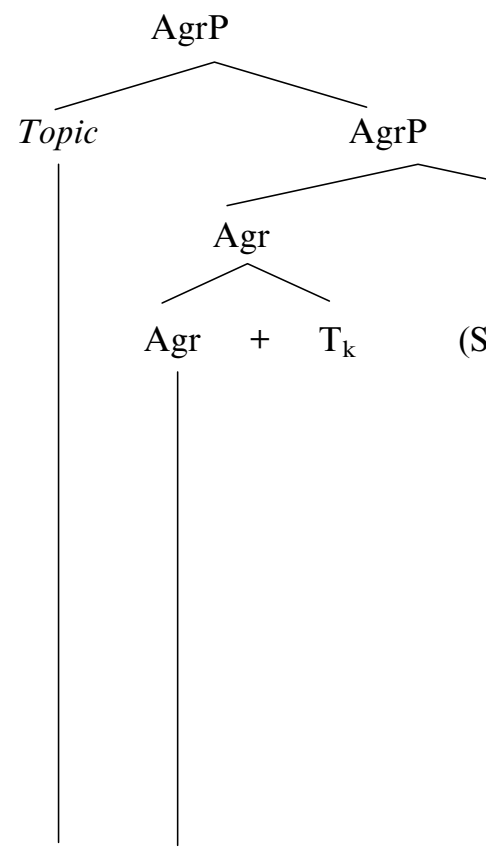

(49) a ik was

b hij was

(50) a die was

b die meisje was

c dan was
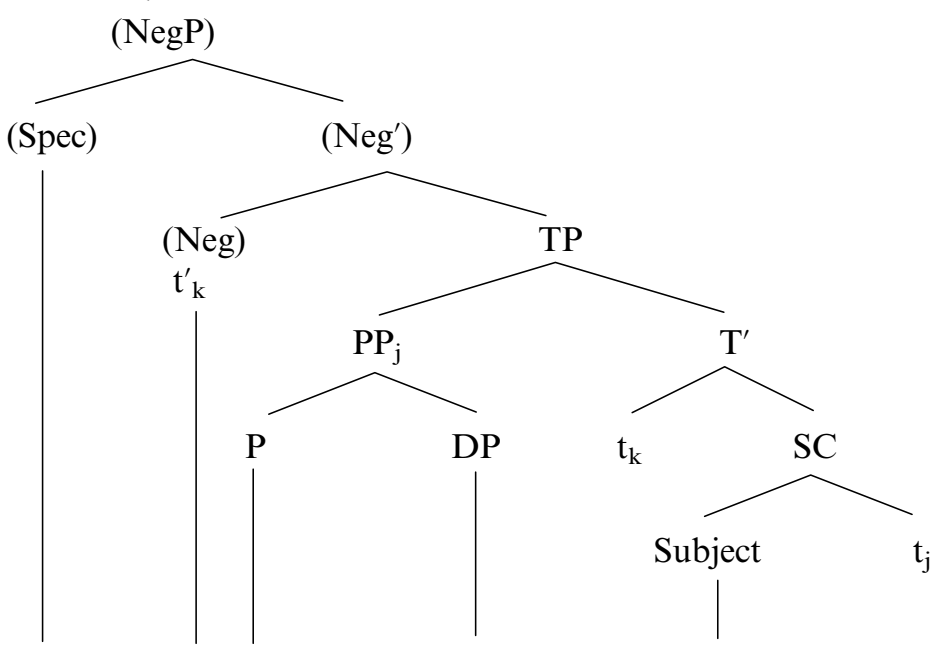

$-\quad-\quad-$

$\varnothing \quad$ pro

$-\varnothing \quad$ pro

ruzie met leraar verkering met een meisje 30 jaar nooit - heeft - 3SG verkering $-\quad-$ heeft - $3 \mathrm{SG} \quad$ een huis

HassanK bases himself on the L1 structure. The structure of the possessive clauses of (49) and (50) is represented in the tree in (51) above. ${ }^{22}$

$$
\begin{aligned}
& \text { a die was heeft -pro } \\
& \text { he was.COP.PAST.3sG has [Eend }+3 \mathrm{sG}] \\
& 30 \text { jaar } \\
& 30 \text { years } \\
& \text { "he was } 30 \text { years" } \\
& \mathrm{b} \text { die meisje was } \\
& \text { that girl was.COP.PAST.3SG never has } \\
& \text {-pro verkering } \\
& {[\text { Eend }+3 \mathrm{sg}] \text { relationship }} \\
& \text { "that girl was never in a relationship" } \\
& \text { c dan was heeft -pro een } \\
& \text { then was.COP.PAST.3SG has [Eend }+3 \mathrm{SG}] \text { a } \\
& \text { huis } \\
& \text { HASK-18 } \\
& \text { house } \\
& \text { "then he had a house" }
\end{aligned}
$$

On the basis of the clauses in (49) and (50), where HassanK must unfold the structure on which he builds his L2 possessive clauses, we assume that all possessive clauses containing HAVE-forms (including present tense clauses) produced by HassanK are the products of a conserved, L1-based grammar in which

22 The NegP category is only projected for (50b). heeft functions similarly to Eend. ${ }^{23}$ So, it must be concluded that HassanK produces conserved HAVEconstructions for as long as such constructions as those in (49)-(50) occur, viz., until session 18.

\section{Restructuring stage}

The constructions discussed under the rubric "restructuring stage", are classified in this section because they deviate both from the conservation stage and the target state. These clauses point to a <strong > setting of the Spec-related $[-\mathrm{N},-\mathrm{V}]$ feature on AGR. Consider the instances in (52).

(52) a $\left[\right.$ AgrP $[\text { PP met kind }]_{i}\left[\mathrm{sC} \text { een jaar t } \mathrm{t}_{\mathrm{i}}\right]^{24}$ FAT-16 with child one year "the child is one year old"

${ }^{23}$ There is one instance in which the subject pronoun cliticizes on heeft. The subject is in dislocation and referred to by a pronominal suffix. It suggests that the label heef still has the features of the preposition Eend.

(i) die meisje, heef-ze een oom HASK-11 that girl has-she one uncle "that girl has an uncle"

24 Note that the prepositions which occur as L2 equivalents of Eend are met "with", van "of" and bij "at". The L2 lexical item bij is an appropriate equivalent for Eend; HassanK also used met and van. 
Table 6. Indications for target syntactic structures of possessive HAVE-constructions

\begin{tabular}{lllll}
\hline \hline & Fatima & Mohamed & HassanK & HassanM \\
\hline - PP+hebben & - & - & session 20 & session 23 \\
- had as past tense & - & - & session 19 & - \\
- hebben & session 26 & session 10 & session 9: heb & session 9 \\
auxiliary of tense & & & session 10: was & \\
& & & session 24: was/heb \\
\hline \hline
\end{tabular}

b [AgrP [PP bij hem $]_{i}\left[\right.$ sc kief $\left.\left.t_{i}\right]\right] \quad$ HASK-20 at him hashish

"he has hashish"

In (52a, b), a syntactic change has taken place with regard to the L1 structure because a PP including a full noun phrase is moved out of the SC. As such a string cannot be moved to the AGR head, it must be moved to some Spec-position, viz., Spec,AgrP, since there is no motivation for the projection of TP. The instances in (53) point to the presence of the TP projection since the BE-copula is realized in (53b) and the BE-copula is present in the form heeft in (53a) as well.

(53) a AggrP $_{\text {Pp }}$ met Soumiya $]_{i}\left[\right.$ Agr* $^{*}$ heeft $\left[{ }_{\mathrm{TP}} \mathrm{t}^{\prime}{ }_{\mathrm{i}}\right.$ with Soumiya has

[sc veel pijn]]]]

HASM- 23 much pain

"Soumiya suffers very much"

b [AgrP $[\text { PP van de boer }]_{i}\left[\right.$ Agr* $_{\text {is }}$ [TP $t_{i}^{\prime}$ of the farmer is

[sC meer autoos $\mathrm{t}_{\mathrm{i}}$ ]]]]

HASK-27 more cars

"the farmer has more cars"

The example in (53b) is interesting because it shows a variant in which the phi+tense features are spelled out as is (the "normal" copular form), without incorporation of the preposition van, which may have a locative meaning in learner varieties. The example in (53a) is comparable to (53b), but also more problematic, because the preposition met appears overtly in Spec,AgrP and is spelled out in the $[\mathrm{AGR}+[\mathrm{T}+\mathrm{P}]]$-complex as heeft. Although it is not a correct target variant, (53a) is a unique developmental error for HassanM. Such an error provides insight into the syntactic structure of the other possessive HAVE-clauses, and we can infer from these examples that HassanM and HassanK generate their HAVE-clauses on the basis of a <strong $>$ setting of the Spec-related $[-\mathrm{N},-\mathrm{V}]$ feature.

\section{Target state}

It is not easy to decide which constructions must be considered target constructions and which should not, because an inflected form of hebben is not a sufficient indication of a complete L2 structure, as was shown above for Fatima and HassanK. They used heeft as an L2 equivalent of the Moroccan Arabic preposition Eend and based themselves on the Moroccan Arabic syntactic structure. So, we must find other indications as evidence for a target structure, for instance, that:

- the subject DP (the possessor) appears in Spec,Agr (evidence for a < strong > setting of the Spec-feature on AGR). It is difficult, however, to distinguish a DP in Spec,Agr from a DP in a position adjoined to AgrP, the more so because a pause between a dislocated DP and the clause is often hardly perceptible. Clear evidence for a $<$ strong $>$ AGR feature is the (incorrect) movement of a full PP (P+DP) to Spec,AGR, as found for HassanK and HassanM in (53);

- the past tense of hebben is expressed in one verbal form, $h a d$, in AGR (and no longer split up as was heeft);

- the verb hebben has been extended from a possessive copula (in which it may be equivalent to the preposition Eend) to an auxiliary of the perfect tense, e.g., hij heeft gezien "he has seen". ${ }^{25}$ In the latter string heeft must be analyzed as a verbal form in AGR.

As we did for the Turkish learners, we abstract from incorrect subject-verb agreement, subject drop, and general L1 properties of the clause for computing the number of target constructions. Applying these criteria, the first occurrences of a target hebbenconstruction are considered to emerge as given in Table 6.

As can be inferred from Table 6, for Fatima, HAVE-clauses must have a target structure at least from session 26 onwards, for Mohamed from session 10 on, and for HassanM from session 9 on. HassanK

${ }^{25}$ For all learners, Moroccan and Turkish alike, possessive HAVEconstructions emerge nine months or more before auxiliary HAVE-constructions. Note that this acquisition order is comparable to the relationship between the possessive HAVE and the auxiliary HAVE as proposed by Kayne (1993). 
Table 7. Distribution of variants of possessive HAVE-clauses produced by four Moroccan learners over developmental stages

\begin{tabular}{|c|c|c|c|c|c|c|c|c|c|c|c|c|}
\hline \multirow[b]{2}{*}{ Cycles } & \multicolumn{3}{|c|}{ Fatima } & \multicolumn{3}{|c|}{ Mohamed } & \multicolumn{3}{|c|}{ HassanK } & \multicolumn{3}{|c|}{ HassanM } \\
\hline & 1 & 2 & 3 & 1 & 2 & 3 & 1 & 2 & 3 & 1 & 2 & 3 \\
\hline \multicolumn{13}{|l|}{ 1. Conservation stage } \\
\hline CWS: DP+DP & 48 & 62 & 21 & 17 & 10 & 1 & 1 & 7 & 4 & 7 & 1 & - \\
\hline FWS: DP+P+NP & 8 & 2 & - & 1 & - & - & 1 & 1 & 1 & 1 & 1 & - \\
\hline - prepositional heeft & 10 & 26 & 76 & 44 & - & - & 77 & 158 & - & 52 & - & - \\
\hline \multicolumn{13}{|l|}{ BFS: } \\
\hline - Past tense: was & - & - & - & - & - & - & - & 12 & 1 & - & - & - \\
\hline - Past tense: was heeft & - & - & - & - & - & - & - & 3 & - & - & - & - \\
\hline \multicolumn{13}{|l|}{ 2. Restructuring stage } \\
\hline$-\mathrm{PP}+\mathrm{DP}$ & 1 & 3 & 1 & - & 2 & - & - & - & - & - & 1 & - \\
\hline$-\mathrm{PP}+i s+\mathrm{DP}$ & - & - & - & - & - & - & - & 1 & - & - & - & - \\
\hline$-\mathrm{PP}+h e e f t+\mathrm{DP}$ & - & - & - & - & - & - & - & - & - & - & - & 1 \\
\hline \multicolumn{13}{|l|}{ 3. Target state } \\
\hline \multicolumn{13}{|l|}{ - present/past: heeft } \\
\hline - full DP P'sor & - & - & 4 & - & 13 & 19 & - & - & 9 & 1 & 19 & 17 \\
\hline - pronominal DP & - & - & 9 & - & 124 & 131 & - & - & 71 & 14 & 124 & 120 \\
\hline - past: had & - & - & - & - & 1 & - & - & - & 2 & - & - & - \\
\hline Total & 67 & 93 & 111 & 62 & 150 & 151 & 79 & 182 & 88 & 75 & 146 & 138 \\
\hline
\end{tabular}

exhibits a complicated acquisition pattern. He is the "victim" of his conservation strategy. The L1 structure, in which kan is the past tense marker in possessive clauses (cf. (49)-(50)), leads him to use this structure also for all perfect and past tense clauses. ${ }^{26}$ In session 19, HassanK grasps that, in possessive clauses, the past tense of hebben is not split up into two distinct linguistic elements, as illustrated in (54). The derivation of (54a) is given in (54b).

(54) a ik had ruzie met leraar I had troubles with teacher "I had troubles with the teacher"

b $\quad\left[\right.$ AgrP $[\mathrm{PP} i k]_{\mathrm{k}}\left[\mathrm{Agr}^{\prime}\left[\mathrm{AGR}+[\mathrm{T}+\mathrm{P}]_{\mathrm{i}}(=\right.\right.$ had $\left.)\right]$ $\left[\mathrm{TP}\left[\mathrm{T}+\mathrm{P}_{\mathrm{i}}\right]\left[\mathrm{sc}\right.\right.$ [ruzie met leraar] $\left.\left.\left.\left[\mathrm{PP}_{\mathrm{i}} \mathrm{t}_{\mathrm{k}}\right]\right]\right]\right]$

The structure in (54b) indicates that this learner has attained a complete reanalysis of the form heeft, which is now composed of $[\mathrm{AGR}+\mathrm{Tense}+\mathrm{P}]$ features. Therefore, not the entire PP $(\mathrm{P}+i k)$ can be moved upwards, but only what is left over in the PP after the head $\mathrm{P}$ has been moved out, viz., $i k$. This locative $\mathrm{P}$

26 Note that, in Moroccan Arabic, forms of the auxiliary kan "to be" are used to mark past tense in combination with a following durative or with an active participle (see Harrell, 1970, pp. $179-181$ for examples). adjoins to $\mathrm{T}$ (recall that this is impossible in the $\mathrm{L} 1$ ) and the entire $[\mathrm{AGR}+\mathrm{T}+\mathrm{P}]$ complex is spelled out in AGR. This knowledge is not yet transferred by HassanK to the construction in which hebben is used as an auxiliary of tense/aspect.

\section{Results}

How many occurrences of each possessive variant are found in the data of the Moroccan learners and to what extent do they attain target knowledge of the possessive HAVE-clause? The results are brought together in Table 7 and should be considered in relation to Table 5 , in which the variants were presented, and Table 6, in which the notion "target state" was delimited for each of the informants. This delineation is used for counting the results in Table 7.

All learners attained target knowledge of possessive HAVE-constructions, as can be inferred from Table 7. HassanM already did so in the course of the first cycle. All four learners show development in morpheme realization states, although in a very restricted way (compared to the Turkish learners). Fatima, the least advanced learner, and HassanK lag behind the other two informants because they rely on their L1 grammar in the cycles 1 and 2. HassanK, in 

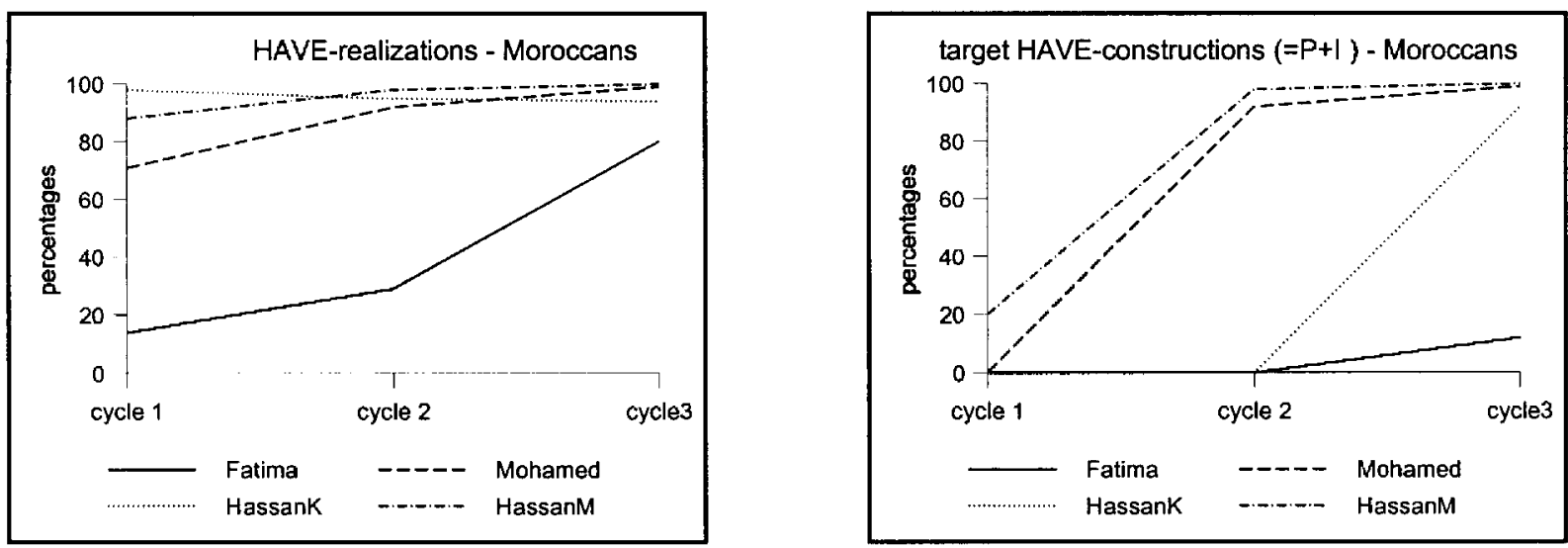

Figure 3. Results on the acquisition of HAVE-constructions produced by four Moroccan learners; left for all realizations of hebben, right for all occurrences interpreted as target constructions.

particular, sticks to the structure of the past tense. This slows down his acquisition process considerably. At the end of the data collection, however, HassanK is able to produce the had-variant in possessive clauses (but not yet as an auxiliary). Consequently, one should conclude that the other informants, who did not display any knowledge of the past tense, were less troubled by the L1 structure but also lag behind in that respect. ${ }^{27}$

To give a clear picture of the acquisition results of the four Moroccan informants and the effect of our interpretation of their data, the percentages of HAVErealizations before and after data interpretation are compared in Figure 3.

The display on the left suggests that three out of four informants use HAVE-constructions in more than $80 \%$ of the cases from cycle 2 on. The graph differs dramatically for HassanK, in particular, because it clearly shows that the early hebben-constructions cannot be target constructions if they are followed by a stage in which was is the past tense of hebben, and heeft the equivalent of Eend. The same holds for Fatima: we do not assume that hebben-constructions are target constructions as long as met and heeft alternate (until session 14), and as long as hebben is not used as an auxiliary (until session 26). The two other informants do not use past tense in possessive constructions, and use the auxiliary only from session 9 and $10 \mathrm{on}$. The figure on the right seems to provide a more realistic picture than the one on the left. Fatima, HassanM and, probably, also Mohamed do not show any knowledge of how to form the past tense in possessive clauses in the L2. In short, we may conclude that, finally, target knowledge of the possessive HAVE-clauses in the present tense is attained by all learners.

27 Except for Mohamed, who produced a single occurrence of had.
HassanK's struggle with the past tense of hebben raises the question how he solved the problem. Until session 18, the BE-copula was not obligatory in HassanK's grammar. In other words, he did not obligatorily project a TP category. From session 19 on, correct HAVE-clauses in the past tense are found. As soon as be becomes obligatory, he discovers the relation between is and was, the tense feature and the projection of TP. Only then, heeft/had can become the spell-out the $[\mathrm{AGR}+[\mathrm{T}+\mathrm{P}]]-$-complex. So, obligatory presence of the BE-copula is the condition for the right syntactic analysis of the HAVE-copula. ${ }^{28}$ The theoretical analysis of copular constructions and the phenomenon of incorporation described by Benveniste, Freeze, Moro and others can also account for HassanK's acquisition problem.

\section{Conclusions}

The first objective of this paper was to describe the acquisition process. Such a description is given in the core tables, Tables 3 and 5, classifying the learners' variants of the eight Turkish and Moroccan learners of Dutch. In those tables, only the first and the last variants are similar for both language groups. The last variant is the target structure and the first learners' variants consist of two noun phrases of the type vader winkel (father shop; "father has a shop"). All phases in between differ for the Turkish and Moroccan learners. The fact that the variant emerging first is identical for both groups of learners is explained by an incomplete vocabulary: only content words and some salient, meaningful functional elements are used. The L1 structure remains hidden

\footnotetext{
28 Mohamed shows similar behavior: the unique occurrence of had in session 17 coincides with obligatory realization of the BEcopula (session 18).
} 
because the order of Possessor and Possessee without morphological elements cannot reveal any L1 structure. In this early stage, learners, particularly slow learners like Mahmut and Ergün (see the description and analysis of the Turkish data) may use chunks in which the clausal construction is not analyzed and L1 properties are not yet exhibited. The L1 structure becomes manifest as soon as the chunk is analyzed (e.g., Ergün in (38)) and morphological elements appear (viz., in the next morpheme realization state). Then L1 properties emerge for both language groups before the target structure is attained.

The second objective was to explain the acquisition process. The analysis of HAVE-clauses as a result of predicate inversion and incorporation of $\mathrm{P}^{0}$ provides an important contribution to the understanding of the Moroccan learners' data, which corroborate the predicate inversion and incorporation analysis. The occurrence of the preposition met and the alternating use of heeft and met support this analysis. A second important piece of evidence for this analysis is the role the BE-copula plays in the acquisition process of possessive HAVE-clauses. Based on this analysis, one would expect that heeft is always the result of incorporation of $\mathrm{P}^{0}$ into the BE-copula. Because adult learners are inclined to use a form like heeft before they can analyze it, this form may emerge before the BE-copula. In this phase, learners cannot make a past tense of hebben. As soon as they discover the function of the TP category for expressing the present tense of the BE-copula, they understand the obligatory character of the BE-copula and only then heeft becomes the spell-out of $[$ Tense $=\mathrm{be}+[\mathrm{AGR}+\mathrm{P}]]$, and this necessarily leads to a past tense variant had. Mohamed showed the same coincidence of obligatory realization of the BE-copula and the first occurrence of the past tense form had. This relationship can only be understood if one adopts the predicate inversion analysis provided by recent linguistic theory.

How to explain that some adult learners in this project come up with target knowledge and others do not, or do so much later? We assume, with Schwartz and Sprouse (1996), that learning an L2 is failure driven. However, we are more explicit at the following points. The environmental input of the L2 is more restricted for L2 learners than for native children acquiring their L1 because L2 learners parse and interpret the L2 data from an L1 perspective. This may mean that they cannot get access to triggers for resetting and, if they can, it is often only after considerable exposure to $\mathrm{L} 2$. We assume that the gradual development of the vocabulary is a restricting factor. As most functional elements bound morphemes more than free morphemes - are learned much later than content words, much linguistic information of the L2 input cannot do its work or only at a much later time. In our view, saliency plays an important role here. It is not only the case that salient lexical items are perceived earlier, but also early L2 learners seem to focus their attention more on those syntactic positions that contain crucial information in their L1. A genitive marker on the possessor is such an element for the Turkish learners. AGR head is such a position for the Moroccan learners. In that position, they find heeft and they take it for the equivalent of Eend. Much later, they discover that the formal features associated with these two phonological matrices are not equivalent and gradually the prepositional features $[-\mathrm{N},-\mathrm{V}]$ are modified in a $[\mathrm{P}+$ tense+ agreement] complex. A condition for this change is that the function of tense for the BE-copula has been discovered so that the locative preposition can successfully be incorporated. As the free functional morpheme of the BE-copula is not very salient, this grammatical information (trigger) can remain hidden for quite a long time, as, for instance, for Fatima.

The third objective was to provide evidence for the conservation of non-parameter-related knowledge, i.e., morphological knowledge and knowledge of lexical items, more particularly, of their formal features. A genitive case marked possessor in HAVEconstructions produced by Turkish learners would be evidence of a conserved $\mathrm{L} 1$ realization rule and a locative preposition instead of a HAVE-form produced by Moroccan learners would be evidence as well. Such forms are found indeed (cf. Tables 3 and 5 for the form and Tables 4 and 7 for the numbers). These outcomes corroborate earlier findings in Van de Craats et al. (2000) on the acquisition of morphological realization rules in the acquisition of possessive nominal phrases and contradict the claim of Eubank (1996), Vainikka and Young-Scholten (1996), and Parodi, Schwartz and Clahsen (1997) that morphology is not susceptible to transfer. Schwartz and Sprouse (1996) are not sufficiently explicit on this point.

The last point we want to touch upon is the question how we can explain the fact that the Moroccan learners have better results than the Turkish learners (see Figure 4 below), in spite of the fact that there was more linguistic knowledge to acquire for Moroccans (cf. Table 1).

In addition to the difference in percentages, it should be noted that the number of occurrences of HAVE-constructions is also higher for Moroccans (see Table 3). The two best Turkish learners in Figure 4a do not exceed $80 \%$ target structures during the third cycle, but they attain a $100 \%$ correct results in the last session, while the two best Moroccan learners 

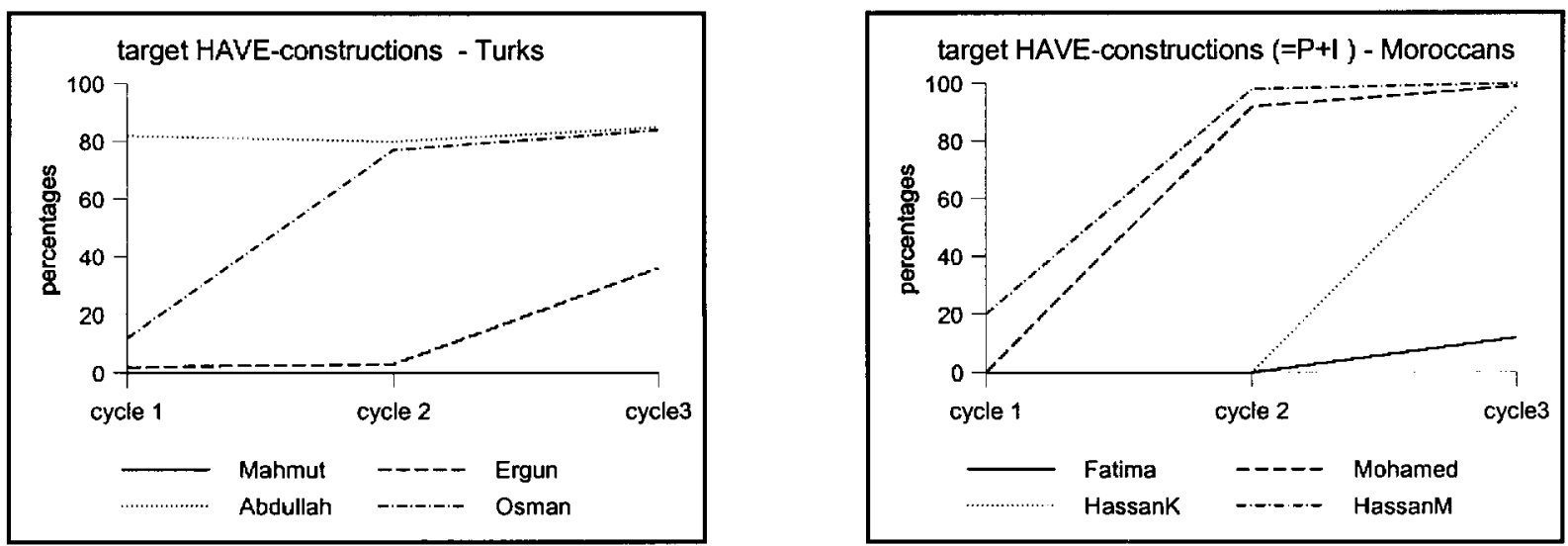

Figure 4. Results of the acquisition of possessive HAVE-constructions produced by four (a) Turkish and four (b) Moroccan learners; Mahmut's results are not visible.

almost have a $100 \%$ correct score in cycle 2 . There are several reasons for this "Turkish delay". In the first place, the Turkish learners attain target HAVEconstructions with a pronominal possessor before they do so for HAVE-constructions with a full DP possessor (see Table 4, target state). It was argued that the pronominal possessor provides more reliable information on its case and, therefore, only pronominal constructions can lead Turkish learners to change the syntactic position in which the possessor is base generated (see Table 1). This differentiation does not play a role for Moroccans. In the second place, the possessor has to drop its morphological properties. We already know from the acquisition of possessive noun phrase that it takes a long time to "get rid of L1 morphology" (see Van de Craats et al. 2000). Moroccan learners seem to acquire the pattern faster because the surface patterns of L1 and L2 look similar. Possibly, they even consider the $\mathrm{P}^{0}$ Eendclitic to be a verbal element (see Caubet's remark cited in footnote 10), which is a fruitful strategy for the acquisition of the present tense but does not necessarily lead to the acquisition of the past tense, as we saw for HassanK.

An additional and interesting outcome of this study is that the possessive copula hebben emerged at a much earlier time (about six months or more) than hebben as an auxiliary of tense/aspect for all the learners in this study. This finding points to a link between possessive clauses and clauses with an auxiliary+past participle construction, as proposed by Kayne (1993). This seems an interesting perspective for further L2 acquisition research on tense and aspect.

By conducting this study on the acquisition of possessive HAVE-constructions, we think we have focussed on a relatively new subject in L2 acquisition research: possessive HAVE-constructions. What is relatively new as well, is the conclusion that "conservation" has a stronger impact than it was often assumed before. Insights from recent linguistic theories help to show this role (as shown before for the acquisition of nominal constructions in the possessive domain).

\section{References}

Benveniste, E. (1966). "Être" et "avoir" dans leurs fonctions linguistiques. Bulletin de la Société de linguistique de Paris, 55 (1), 113-134. Reprinted in Problèmes de linguistique générale. Paris: Gallimard, 1966.

Broeder, P. (1992). Possession in a new language. Applied Linguistics, 13, 2, 100-118.

Caubet, D. (1993). L'arabe marocain. Tome II: Syntaxe et catégories grammaticales. Textes. Paris-Louvain: Editions Peeters.

Chomsky, N. (1981). Lectures on government and binding. Dordrecht: Foris.

Chomsky, N. (1995). The Minimalist Program. Cambridge, MA: MIT Press.

Clark, E. V. (1978). Locationals: Existential, locative and possessive constructions. In J. H. Greenberg (ed.), Universals of human language. Vol. 4: Syntax, pp. 85-126. Stanford, CA: Stanford University Press.

Den Dikken, M. (1994). Predicate inversion and minimality. In R. Bok-Bennema \& C. Cremers (eds.), Linguistics in the Netherlands 1994, pp. 1-12. Amsterdam/ Philadelphia: John Benjamins.

Den Dikken, M. (1998). Predicate inversion in DP. In A. Alexiadou \& Ch. Wilder (eds.), Possessors, predicates and movement in the determiner phrase, pp. 177-214. Amsterdam \& Philadelphia: John Benjamins.

Eubank, L. (1996). Negation in early German-English interlanguage: More valueless features in the L2-initial state. Second Language Research, 12, 73-106.

Freeze, R. (1992). Existentials and other locatives. Language, 68, 553-595. 
Haegeman, L. (1994). Introduction to government and binding theory. Oxford: Blackwell.

Haegeman, L. \& Zanuttini, R. (1991). Negative heads and the Neg criterion. The Linguistic Review, 8, 233-252.

Hamburger, H. (1980). A deletion ahead of its time. Cognition, 8, 389-416.

Harrell. R. (1970). A short reference grammar of Moroccan Arabic. Washington, DC: Georgetown University Press.

Heycock, C. \& Kroch, A. (1996). Pseudocleft connectivity: Implications for the LF interface level. Paper presented at GLOW 19, Athens. Ms., University of Edinburgh \& University of Pennsylvania.

Hoekstra, T. \& Mulder, R. (1990) Unergatives as copular verbs: Locational and existential predication. The Linguistic Review, 7, 1-79.

Kayne, R. S. (1993). Towards a modular theory of auxiliary selection. Studia Linguistica, 47, 3-31.

Kitagawa, Y. (1986). Subject in Japanese and English. Ph.D. dissertation, University of Massachusetts, Amherst.

Klein, W. \& Perdue, C. (1997). The basic variety, or: Couldn"t natural languages be much simpler? Second Language Research, 13, 301-347.

Koopman, H. \& Sportiche, D. (1991). The position of subjects. Lingua, 85, 211-258.

Kornfilt, J. (1997). Turkish. London, New York: Routledge.

Lewis, G. L. (1967). Turkish grammar. Oxford: Oxford University Press.

Lyons (1968). Existence, location, possession and transitivity. In B. van Rootselaar \& T. F. Staal (eds.), Logic, methodology, and philosophy of science, vol. III, pp. 495-509. Amsterdam: North Holland Publishing Co.

Moro, A. (1990). There-raising: Principles across levels. Paper presented at GLOW, Cambridge.

Moro, A. (1997). Predicative noun phrases and the theory of clause structure. Cambridge: Cambridge University Press.

Parodi, T. (2000). Finiteness and verb placement in second language acquisition. Second Language Research, 16.4, $355-381$.
Parodi, T., Schwartz, B. D. \& Clahsen, H. (1997). On the L2 acquisition of the morphosyntax of German nominals. Essex Research Reports in Linguistics, 15, Colchester: University of Essex, 1-43.

Perdue, C. (1993). Adult language acquisition: Cross-linguistic perspectives. Cambridge: Cambridge University Press.

Powers, S. M. \& Musolino, J. (1997). Precursor relative clauses in the acquisition of English. In A. Sorace, C. Heycock \& R. Shillcock (eds.), GALA '97 conference on language acquisition, pp.126-131. Edinburgh.

Roeper, T. (1999). Universal bilingualism. Bilingualism: Language and Cognition, 2 (3), 169-186.

Schwartz, B. D. \& Sprouse, R. A. (1996). L2 cognitive states and the Full Transfer/Full Access model. Second Language Research, 12, 40-72.

Sportiche, D. (1981). Bounding nodes in French. The Linguistic Review, 1.2, 219-246.

Stowell, T. (1983). Subjects across categories. The Linguistic Review, 2, 285-312.

Szabolcsi, A. (1992). The noun phrase. In F. Kiefer \& K. Kiss (eds.), The syntactic structure of Hungarian (Syntax and Semantics 27), pp. 179-274. San Diego, CA: Academic Press.

Taeschner, T. (1983). The sun is feminine: A study on language acquisition in bilingual children. Berlin/ Heidelberg: Springer.

Travis, L. (1984). Parameters and effects of word order variation. Ph.D. dissertation, MIT.

Vainikka, A. \& Young-Scholten, M. (1996). Gradual development of L2 phrase structure. Second Language Research, 12, 7-39.

Van de Craats, I., Corver, N. \& Van Hout, R. (2000). Conservation of grammatical knowledge. On the acquisition of possessive noun phrases. Linguistics, 38.2, 221-314.

Van Kampen, J. (1997). First steps in wh-movement. Ph.D. dissertation, University of Utrecht.

Received November 20, 2001 Revision accepted March 27, 2002 